\title{
Baseline Postirradiation Examination of Fuel Rodlets from the AFC-2D Experiment*
}

Fuel Cycle Research \& Development Advanced Fuels Campaign

Jason M. Harp

*Note that this document is prepared from materials presented in INL/LTD-15-36358

Prepared for GenIV SFR-AF PMB

July 2017

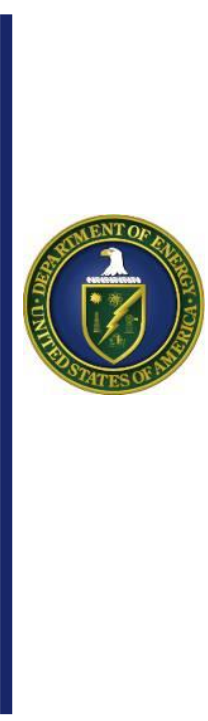




\section{DISCLAIMER}

This information was prepared as an account of work sponsored by an agency of the U.S. Government. Neither the U.S. Government nor any agency thereof, nor any of their employees, makes any warranty, expressed or implied, or assumes any legal liability or responsibility for the accuracy, completeness, or usefulness, of any information, apparatus, product, or process disclosed, or represents that its use would not infringe privately owned rights. References herein to any specific commercial product, process, or service by trade name, trade mark, manufacturer, or otherwise, does not necessarily constitute or imply its endorsement, recommendation, or favoring by the U.S. Government or any agency thereof. The views and opinions of authors expressed herein do not necessarily state or reflect those of the U.S. Government or any agency thereof. 
INL/MIS-17-42675

Revision 0

\title{
Baseline Postirradiation Examination of Fuel Rodlets from the AFC-2D, Experiment
}

\author{
Jason M. Harp \\ July 2017 \\ Idaho National Laboratory \\ Idaho Falls, Idaho 83415
}

http://www.inl.gov

Prepared for

GenIV SFR-AF PMB 
INTENTIONALLY BLANK 


\section{CONTENTS}

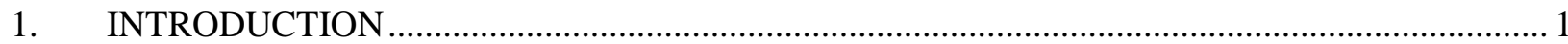

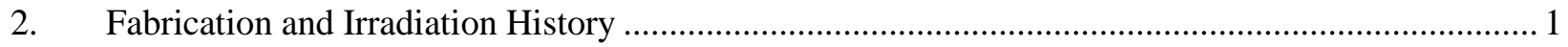

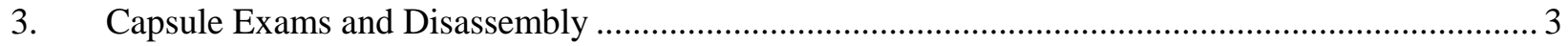

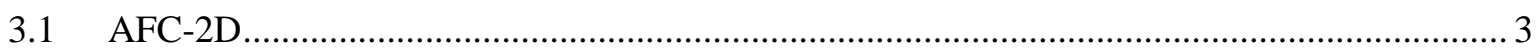

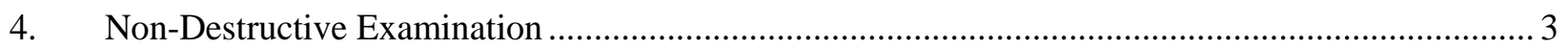

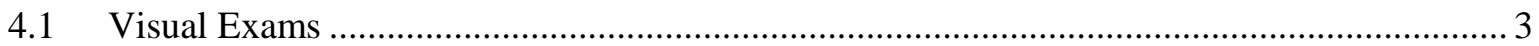

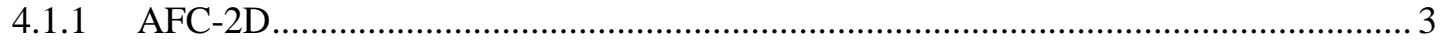

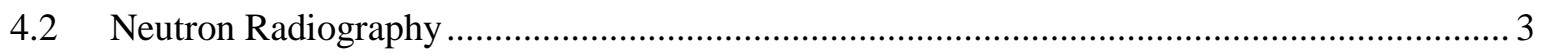

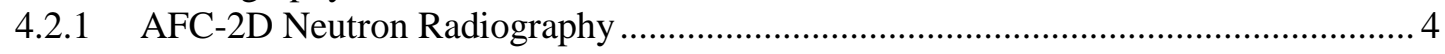

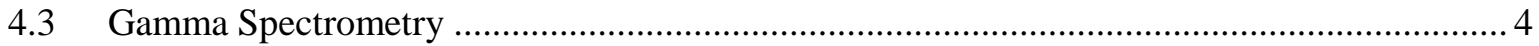

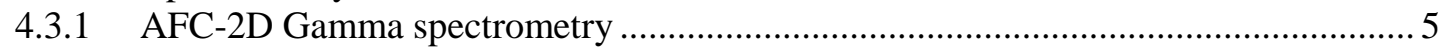

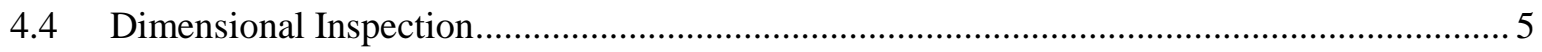

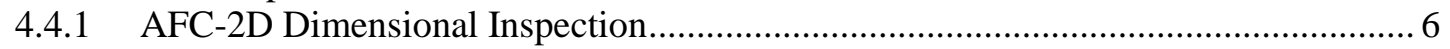

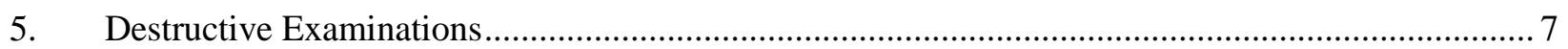

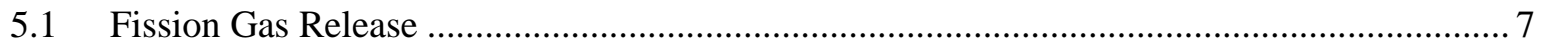

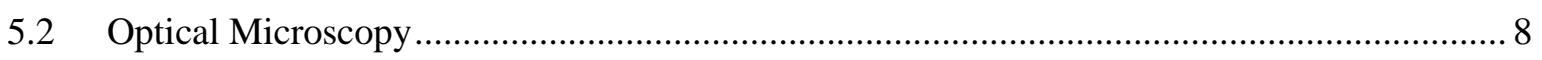

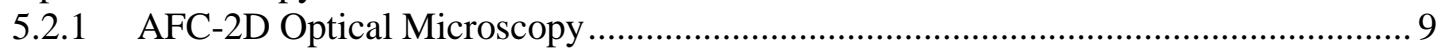

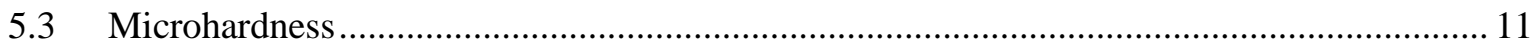

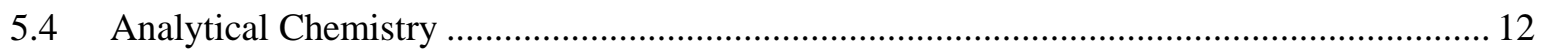

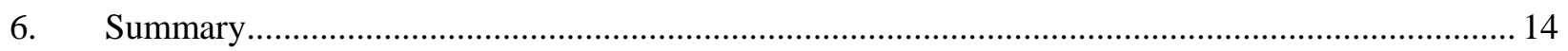

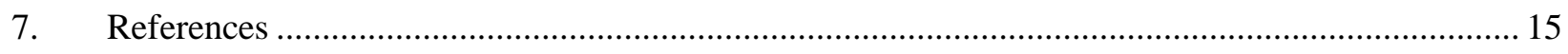

FIGURES

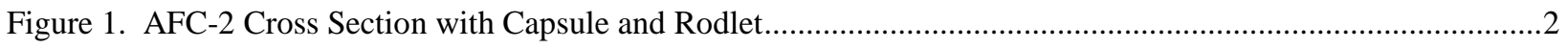

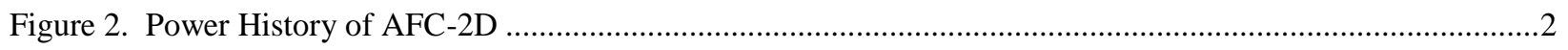

Figure 3. AFC-2D R1 visual exam by through window photography ..............................................................

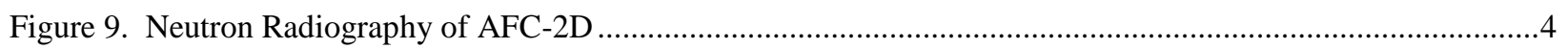

Figure 5. Gamma spectrometry of AFC-2D Rodlet 2 with neutron radiography .....................................................5

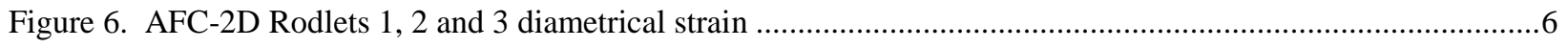

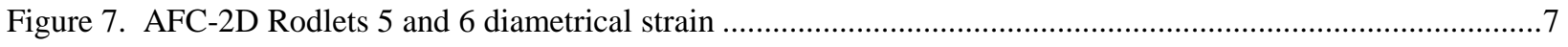

Figure 8. AFC-2D optical microscopy (images recorded at 50X magnification) …...............................................

Figure 9. FCCI comparison between higher and lower O/M ratio MA-MOX of similar burnup ...............................10

Figure 10. Fission gas bubbles on grain boundary in AFC-2D R6 cross section near center of the fuel (500X image). 
Figure 11. Intragranular fission gas bubbles in AFC-2D R6 cross section in the periphery of the fuel (200X

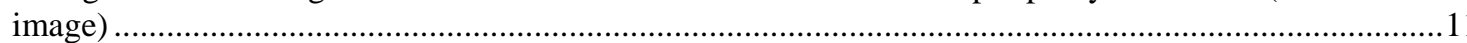

\section{TABLES}

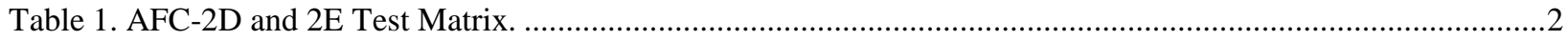

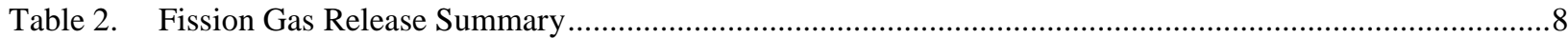

Table 3. Summary of microhardness testing from different rodlet cross sections ………........................................12

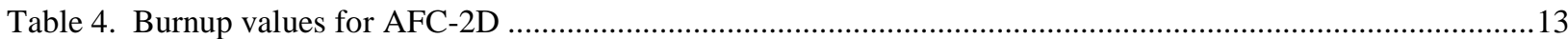




\section{Baseline Postirradiation Examination of the AFC-2D, Experiment}

\section{INTRODUCTION}

Baseline postirradiation exam (PIE) has been completed on experiments from the Advanced Fuels Campaign (AFC) AFC series of experiments. The Advanced Fuels Campaign is a part of Fuel Cycle Research \& Development (FCRD) that seeks to develop and demonstrate the technologies needed to transmute long-lived transuranic actinide isotopes contained in spent nuclear fuel via fast reactor technology. As part of this development, candidate nuclear fuels and possible transuranic transmutation compositions undergo irradiation testing in a prototypic fast reactor spectrum. Postirradiation examination of these materials provides data on the in reactor fuel performance and input into future fuel design choices [1].

Observations from the AFC-2D experiment are recorded here [2]. The examined AFC-2 experiment is a continuation of studying fast reactor and transmutation fuel begun by other AFC experiments [3, 4]. The AFC-2D experiment was designed to examine the high burnup irradiation performance of mixed oxide (MOX) and minor actinide mixed oxide (MA-MOX) fuel in a predominately fast neutron spectrum. The same compositions irradiated in AFC-2D were irradiated to a lower burnup in AFC-2C. The PIE results from AFC-2C were previously reported in Reference 5. Key performance parameters are irradiation growth and swelling, He and fission gas release fractions, fission product and fuel constituent migration, and fuel cladding chemical interaction (FCCI). Additional data collected from this irradiation can be compared to the historic data collected on other minor actinide MOX irradiated in historic fast reactors such as FFTF. Interpretation of all these experiments rests on a basic understanding of the prior history of fast reactor fuel performance which has been summarized periodically in the literature $[6,7,8,9]$.

Experiments in the AFC series all undergo a standard set of PIE measurements. Visual exams of all capsules are followed by neutron radiography and gamma spectrometry. These exams are used to identify the experiments and provide a first look to determine if anything unexpected has occurred during irradiation. They also help guide disassembly of the capsules. After the capsules are disassembled, the rodlets are visually examined, and undergo neutron radiography and gamma spectrometry in more detail than with the capsule scans. The rodlets are inspected for any change in their axial or radial dimensions. These non-destructive exams are performed on all rodlets, and then rodlets go through various different destructive exams including: fission gas release and plenum volume analysis, metallography, microhardness testing and chemical burnup analysis. These non-destructive and destructive exams are considered the "baseline" and will be reported here. Some additional non-destructive exams, namely gamma-ray tomography of select rodlets, have also been performed. If radiation levels are low enough, samples from optical metallography may be sent for further electron microscopic analysis and other advanced characterization techniques in the future.

This report focuses on the results from the different examinations performed in the Hot Fuel Examination Facility (HFEF) hot cell and other facilities. Descriptions of equipment used to collect the relevant data are provided as is necessary for interpretation of the data. A more detailed description of the equipment and the data collection methodology can be found in Reference 10 and Reference 11.

\section{Fabrication and Irradiation History}

The AFC-2D irradiation test geometry, rodlet composition, and irradiation history are summarized in this section to provide clarity when interpreting the PIE results. The fabrication and pre-irradiation characterization of AFC-2D is documented in Reference 12 and 13, and the irradiation goals are outlined in Reference 14. The AFC-2 series was irradiated in the ATR East Flux. An illustrations of the cross section of both the AFC-2 is shown in. Each AFC experiment consists of a fuel material (actinide alloy or compound) encapsulated in a sealed cladding material (HT-9 ferritic martensitic steel), and further encapsulated in a stainless steel capsule that serves as the primary boundary between the ATR primary coolant and the experiment. The power in the rodlets is driven by the power of the ATR, and the enrichment of the fuel material is tailored to give the programmatically desired linear heat generation rate at the expected ATR power conditions. The gas gap between the rodlet and the capsule is used to control the irradiation temperature in the rodlet given some linear heat generation rate. The fuel material and the cladding material are referred to as the "rodlet," and the stainless steel capsule is referred to as the "capsule." When positioning the experiments in different ATR positions, the capsules are placed in "baskets." This experiment utilized a Cd-shrouded basket to eliminate thermal neutrons thus creating a neutron energy spectrum that is closer to a fast reactor spectrum 


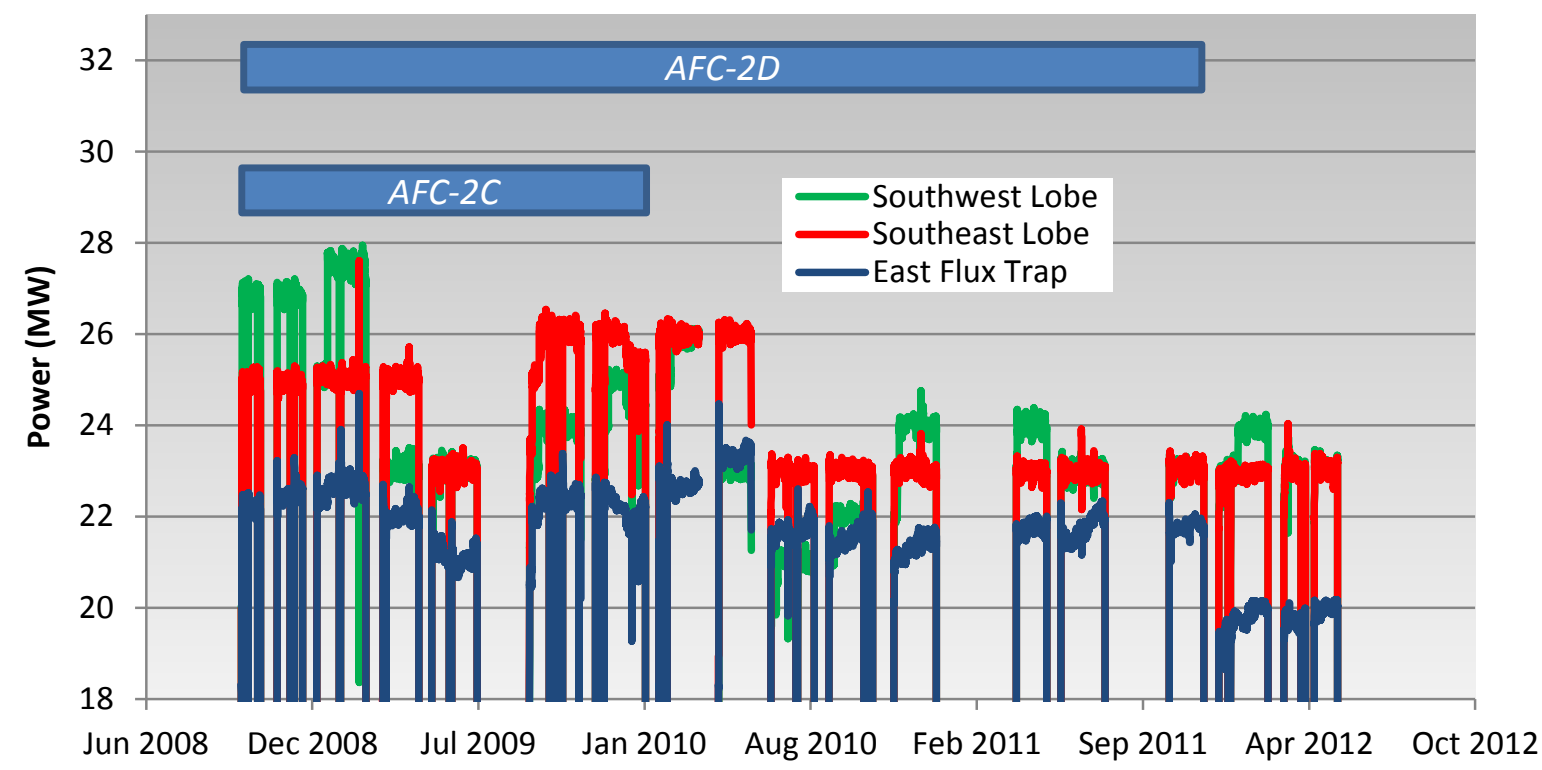

Figure 2. Power History of AFC-2D

than can normally be achieved in a thermal neutron reactor such as ATR. AFC-2 rodlets were encapsulated in a single capsule. It should be noted that Figure 1 does not include the Cd-shrouded basket.

The nominal composition of the AFC-2D rodlets is shown in Table 1. No fuel was irradiated in rodlet 4 because of concerns that the power in that position would be too high causing unacceptably high fuel and cladding temperatures. The actual compositions varied slightly and can be acquired from Reference 12 for AFC-2D. Most notably the oxygen to metal $(\mathrm{O} / \mathrm{M})$ ratios for the MOX were higher than the nominal compositions. The MOX fuel had an O/M of 1.982, the nominal $1.98 \mathrm{O} / \mathrm{M}$ MA-MOX had an O/M of 1.986, and the $1.95 \mathrm{O} / \mathrm{M}$ MA-MOX had an $\mathrm{O} / \mathrm{M}$ of 1.962 [12]. Higher O/M ratios increase the likelihood of FCCI in MOX fuels.

The as-run irradiation conditions of all the experiments are captured in as-run ECAR's for each ATR cycle. AFC2D was in ATR from cycle 143A (9/23/2008) to 150B (11/26/2011) [15 to 28]. The power of the AFC-2 experiments was dominated by the East Flux Trap power which is plotted in Figure 2. The time period each test was in the reactor and the hourly power history that drove the different experiments is all plotted in Figure 2.

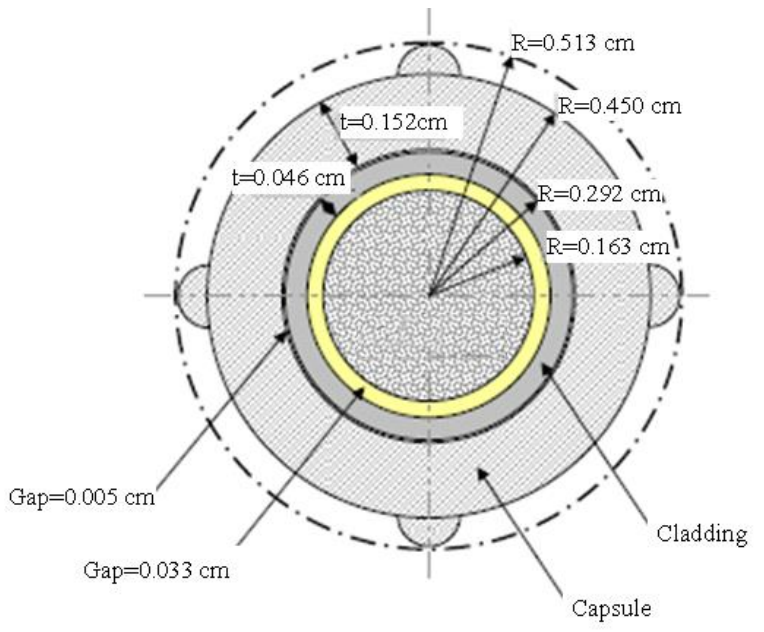

Figure 1. AFC-2 Cross Section with Capsule and Rodlet
Table 1. AFC-2D and 2E Test Matrix.

\begin{tabular}{ll}
\hline Rodlet ID & Nominal Composition \\
\hline AFC-2D R1 & $\left(\mathrm{U}_{0.75}, \mathrm{Pu}_{0.20}, \mathrm{Am}_{0.03}, \mathrm{~Np}_{0.02}\right) \mathrm{O}_{1.95}$ \\
AFC-2D R2 & $\left(\mathrm{U}_{0.8}, \mathrm{Pu}_{0.2}\right) \mathrm{O}_{1.98}$ \\
AFC-2D R3 & $\left(\mathrm{U}_{0.75}, \mathrm{Pu}_{0.20}, \mathrm{Am}_{0.03}, \mathrm{~Np}_{0.02}\right) \mathrm{O}_{1.98}$ \\
AFC-2D R4 & -- \\
AFC-2D R5 & $\left(\mathrm{U}_{0.75}, \mathrm{Pu}_{0.20}, \mathrm{Am}_{0.03}, \mathrm{~Np}_{0.02}\right) \mathrm{O}_{1.95}$ \\
AFC-2D R6 & $\left(\mathrm{U}_{0.75}, \mathrm{Pu}_{0.20}, \mathrm{Am}_{0.03}, \mathrm{~Np}_{0.02}\right) \mathrm{O}_{1.98}$ \\
\hline
\end{tabular}

Numbers preceding an element indicate weight \%

Subscript numbers indicate atomic \% 


\section{Capsule Exams and Disassembly}

Before rodlets are removed from their capsules, the capsules undergo a series of non-destructive exams (NDE) to verify nothing catastrophic has occurred during irradiation or shipment and to help identify the location of the rodlets in the capsule. Visual exams, neutron radiography, and gamma spectrometry are performed on all rodlets before disassembly.

\subsection{AFC-2D}

Visual exams, neutron radiography, and gamma spectrometry were performed on the AFC-2D rodlets before disassembly. Nothing remarkable was seen in the visual exams or the gamma spectrometry. The neutron radiography was used to guide the sectioning of the AFC-2D capsule. The capsule neutron radiography indicated that the AFC2D rodlets appeared to largely be intact. Disassembly proceeded with caution. AFC-2 capsules were disassembled by sectioning per the neutron radiography to create capsule pieces that contained individual rodlets. This is followed by using an in-cell mill to cut two flats on the capsule tubing walls that were cut $180^{\circ}$ apart. The flats penetrate through the majority of the capsule wall thickness of $0.152 \mathrm{~cm}$. The milled capsule pieces were then placed in a chucking device that could mechanically grip the capsule wall where the flats had been milled. The capsule could then be mechanically opened in a "clam-shell" fashion. This methodology worked very well for both the AFC-1 and the AFC-2 series.

\section{Non-Destructive Examination}

After the rodlets were removed from the capsules, they were run through the standard set of exams. This includes visual examination, neutron radiography, gamma spectrometry, and dimensional inspection.

\subsection{Visual Exams}

Visual exams are currently performed by through window photography. The rodlets are placed on a neutral background fixture with a scale. The fixture is held in place by one of the in-cell electro-mechanical manipulators. After the initial photograph is taken the rodlets are rotated and at least a second angle is taken.

\subsubsection{AFC-2D}

The visual exam of AFC-2D did not reveal any obvious flaws in the cladding. The cladding in the fueled region was noticeably discolored. AFC-2D R1 is shown in Figure 3, and visual exam shots of all the AFC-2D rodlets are in Appendix A.

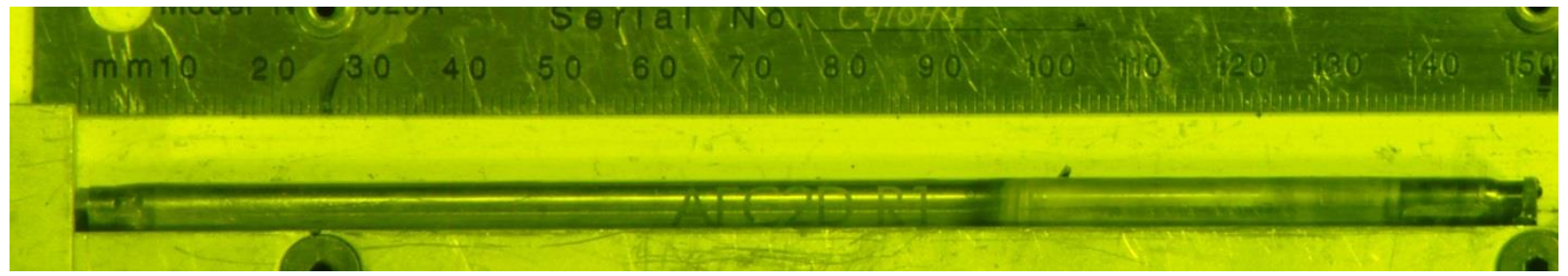

Figure 3. AFC-2D R1 visual exam by through window photography

\subsection{Neutron Radiography}

Neutron radiography was performed with the HFEF NRAD reactor which is a $250 \mathrm{~kW}$ TRIGA reactor located in the basement of HFEF. Items being radiographed are lowered down to the sub-cell area in a specimen positioning tube that penetrates the main hot cell floor. Neutrons pass through the specimen and expose different activation foils. The foils are then used to expose film that is then developed to create radiographs. Cadmium filtered indium foils are used for epithermal neutron imaging and dysprosium foils are used for thermal neutron imaging. The radiography fixture contains a scale marked with Gd paint that produces a scale for quantitative measurements of fuel stack dimensional changes. 


\subsubsection{AFC-2D Neutron Radiography}

All the rodlets from AFC-2D were shot together in a single radiography shot. The thermal and epithermal radiography images for AFC-2D are shown in Figure 9. No massive failures or significant decomposition was detected in the radiography. The top and bottom pellets in each pellet stack are depleted $\mathrm{UO}_{2}$ insulator pellets. These pellets help flatten variations in the axial flux and axial temperature profile. As expected, the contrast in the epithermal shot can be manipulated to reveal low attenuation regions in the center of some of the pins (R2, R3, R5) that are indicative of central void formation. Optical microscopy confirmed central void formation in these rodlets. There is a large void in the top insulator pellet of AFC-2D R3. This rodlet was reshot during the AFC-3 neutron radiography shots and revealed the same feature. Exactly what has caused this feature has not been investigated at this time, but it may be related to void formation lower in the fuel stack.

\subsection{Gamma Spectrometry}

Gamma spectrometry of all of the rodlets was performed using the HFEF Precision Gamma Scanner (PGS). The PGS has three major components: collimator, stage, and detector. The collimator penetrates the HFEF cell wall with a rectangular aperture that is adjustable form $0.254 \mathrm{~cm}$ to $0.00254 \mathrm{~cm}$ in height and is $2.2225 \mathrm{~cm}$ wide. The collimator can be rotated from a horizontal to vertical orientation. The stage manipulates the sample in front of the collimator in the plane facing the collimator and can rotate the sample about its central axis. The detector consists of a Compton suppressed High Purity Germanium (HPGe) detector and its control system moves the stage and collimator and initiates scans.

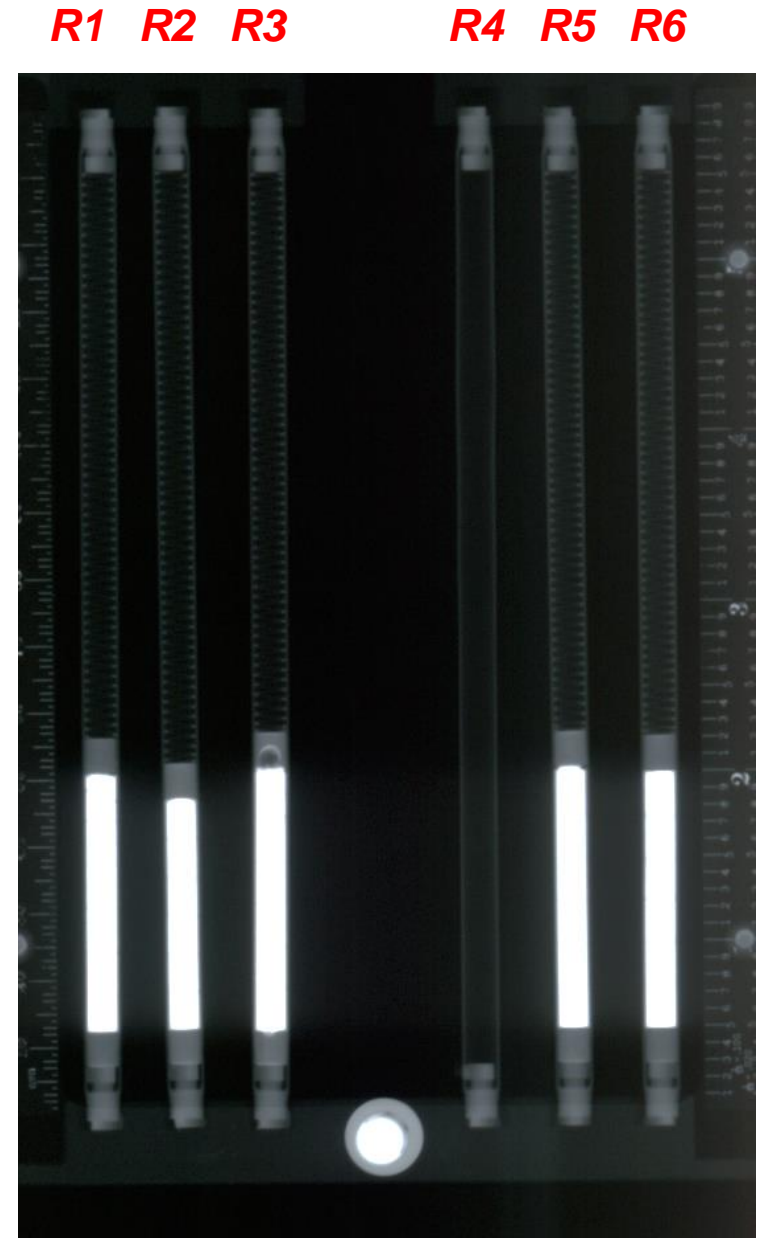

Thermal

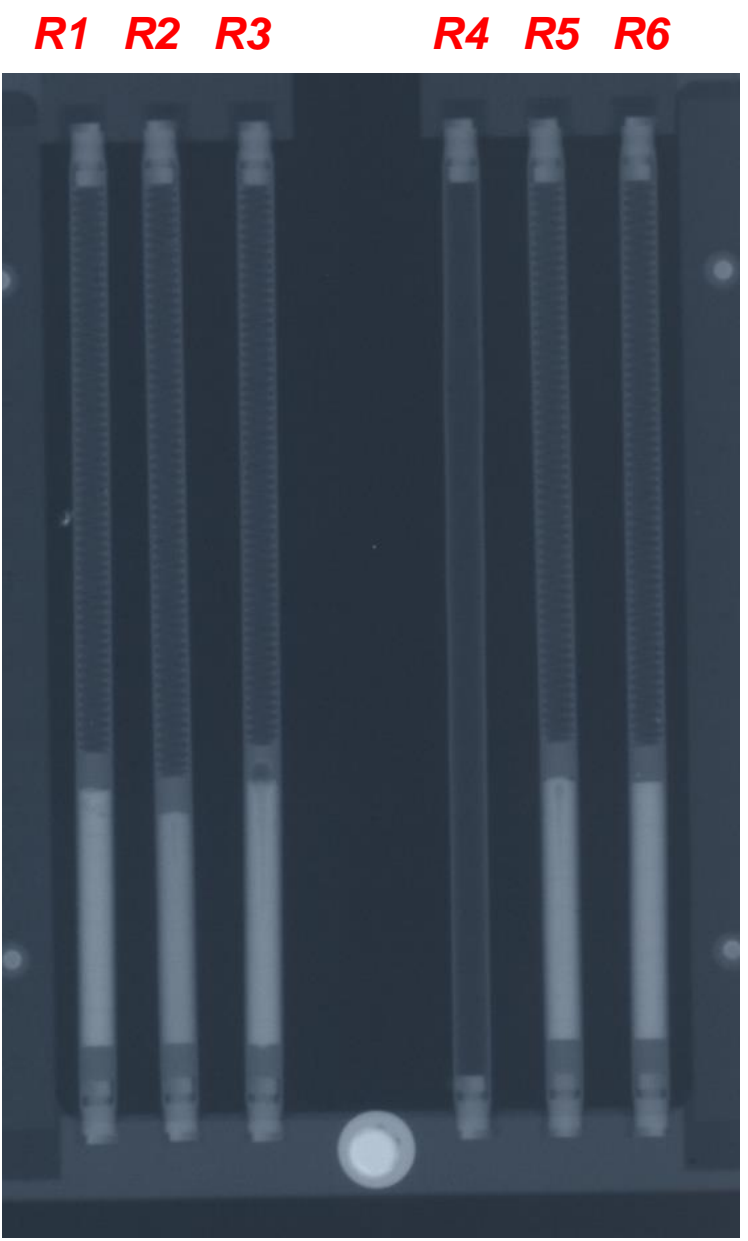

Epithermal

Figure 4. Neutron Radiography of AFC-2D 


\subsubsection{AFC-2D Gamma spectrometry}

The AFC-2D experiment was scanned axially in $0.127 \mathrm{~cm}$ steps with the collimator set to 0.127 and each scan had a live time of 5 minutes. There were 7 fission products that were strongly detected in the gamma spectrometry (Ru-106, Cs-134, Cs-137, Eu-154, Ce-144, Zr-95, Nb-95) and 2 activation products (Co-60, Mn-54). With the exception of Cs, the gamma emitting fission products remained in the fuel. Cs appears to have migrated out of the fuel and collected in the cooler plenum. The central fuel regions were likely hot enough to prevent the formation of Cs oxides and kept the Cs in an elemental vapor [33] allowing it to escape through the central void into the plenum. The behavior of all the detected isotopes is summarized in Figure 5. In the figure, the RuRh-106 line is representative of the axial distribution of Ru-106 and all the other detected fission products besides Cs. The fission products are concentrated in the enriched pellets where most of the fission occurred. The location of the enriched pellets can be seen in the darkest areas of the neutron radiography. The Mn-54 line represents the behavior of Mn-54 and Co- 60 . These activation products are highest in the end-caps where there is more steel to activate. The Cs-137 line is representative of both Cs-137 and Cs-134. The activity peak around $41.5 \mathrm{~cm}$ likely represents the axial location where the plenum cooled enough to immobilize the Cs vapor phases. Local variations in the fission product signal in the fuel stack may be due to scanning the interface between two pellets or heterogeneity in the as-fabricated pellets. Additional plots of the gamma spectrometry of the other AFC-2D rodlets are in Appendix B.

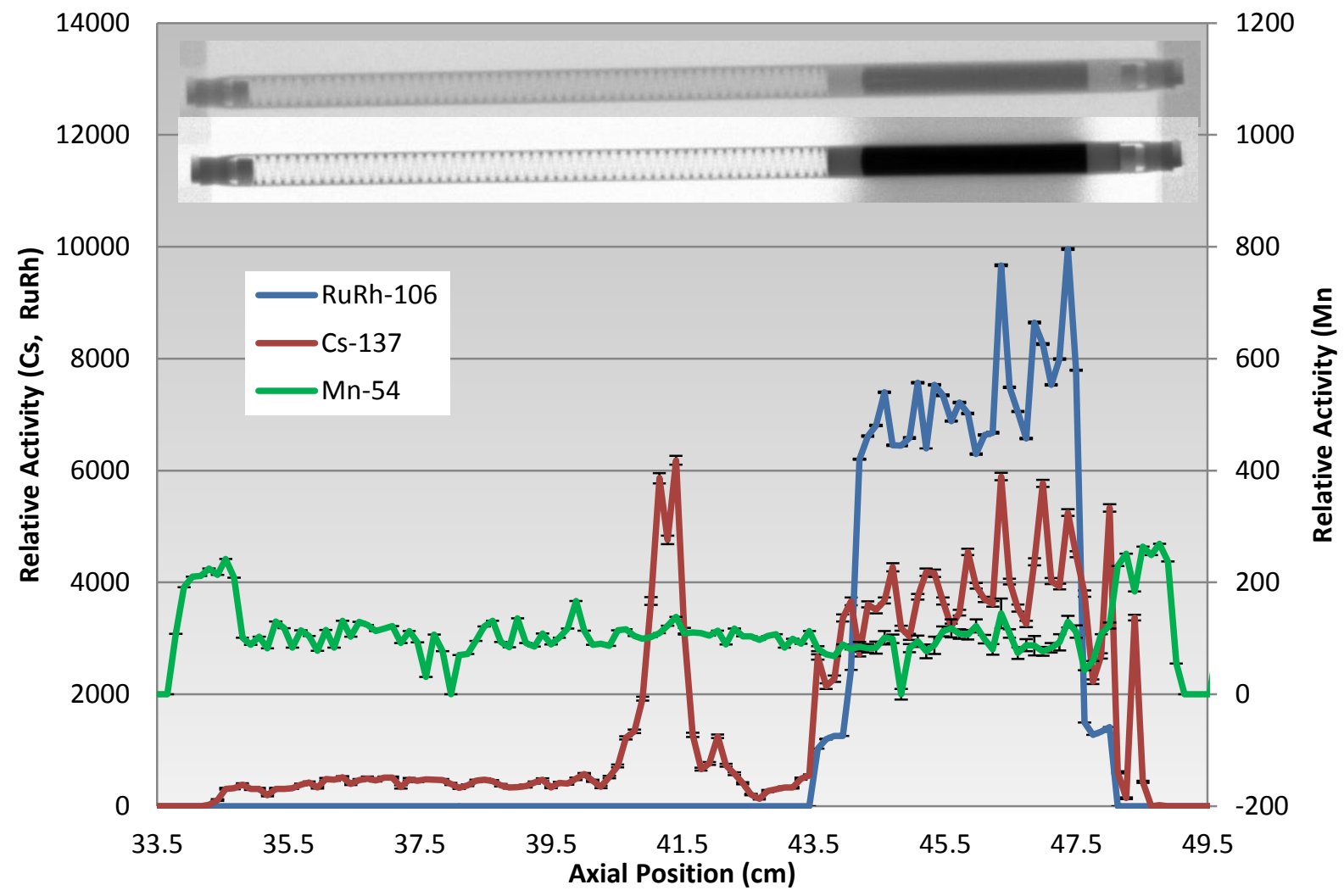

Figure 5. Gamma spectrometry of AFC-2D Rodlet 2 with neutron radiography

\subsection{Dimensional Inspection}

Dimensional inspection of the rodlets was performed with the HFEF Plate and Rodlet checker. This system uses contact sensors to determine the diameter of a rodlet at a specific axial location. The instrument also collects several diameter measurements at a single axial location for a specified number of angles. Rodlets were examined every $0.127 \mathrm{~cm}\left(0.050 \mathrm{in}\right.$.) at 5 angles $45^{\circ}$ apart (the $5^{\text {th }}$ angular measurement should have matched the first and was used to confirm measurements). The accuracy of the diameter measurements are $\pm 0.0005 \mathrm{~cm}(0.002 \mathrm{in}$.). Often a diameter trace will contain a single point spike that is cause by small amounts of dust or other contaminants on the rodlet surface. Deformation of the rodlet that makes the cladding an oval shape will also appear in the measurements, but 
diameter growth in one angle will be matched by diameter shrinkage in other angles. Because of these anomalies, definite trends in diameter change are needed before a rodlet is considered to have actually deformed due to irradiation.

\subsubsection{AFC-2D Dimensional Inspection}

AFC-2D displayed more diametral strain than AFC-2E or AFC-3A/B and more strain than the sister rodlets from AFC-2C. The diametral strain of each fueled rodlet is shown in Figure 6 and Figure 7 along with the maximum possible strain that is defined as swelling all the way to the capsule inner wall diameter. The strain is all present in the fueled region of the rodlets (right side of the figures) and the spikes in the measurements above the fueled region are likely from dust or other contaminants on the rodlets. The diametral strain in the fueled region is between 1.0 and $1.6 \%$ for all the rodlets. AFC- $2 \mathrm{C}$ rodlet 3 had a maximum strain of $0.5 \%$ which was the maximum strain in all AFC$2 \mathrm{C}$ rodlets excluding $\mathrm{AFC}-2 \mathrm{C}$ rodlet 4 which likely swelled to the capsule inner diameter [5].

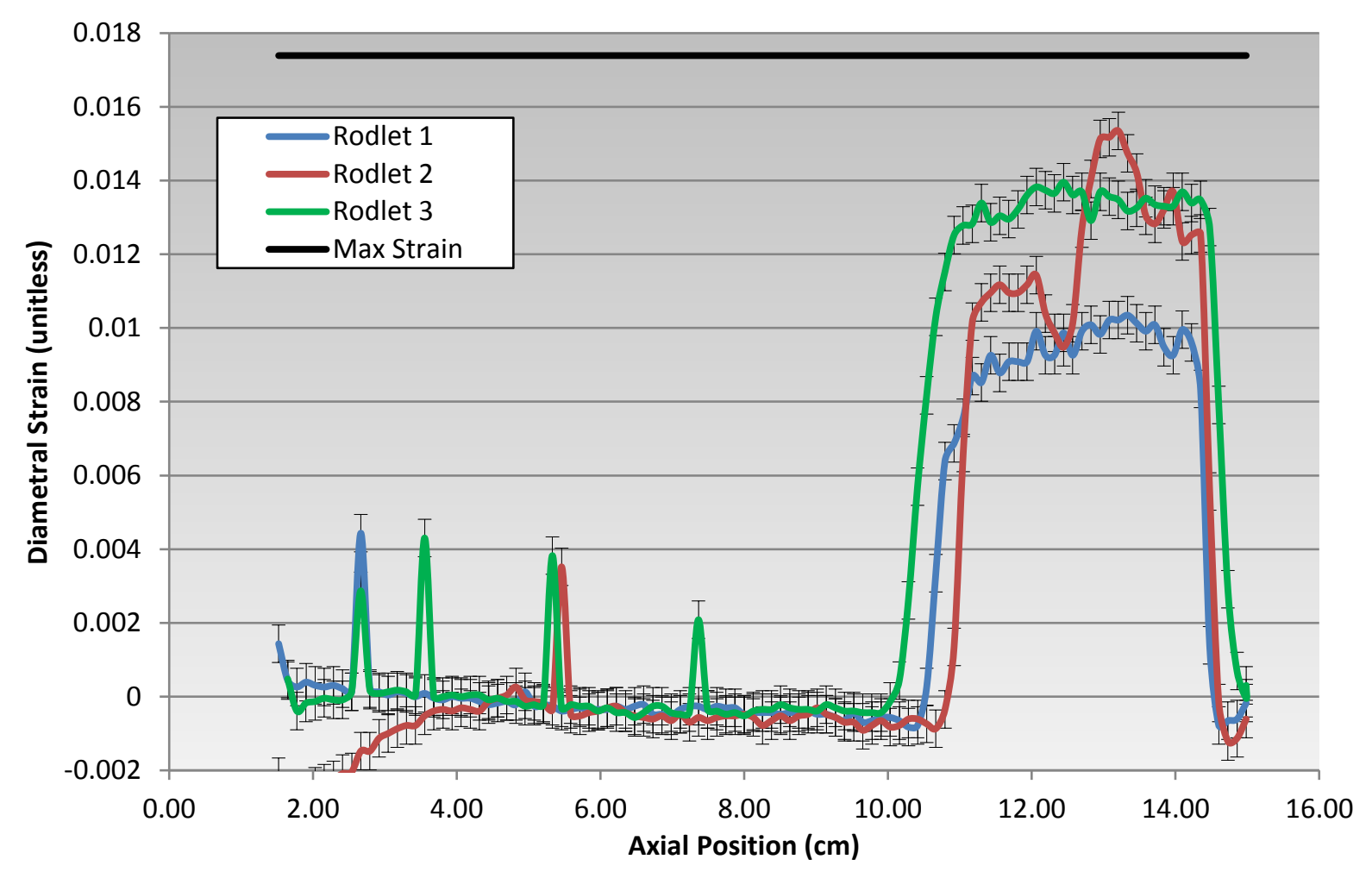

Figure 6. AFC-2D Rodlets 1, 2 and 3 diametrical strain 


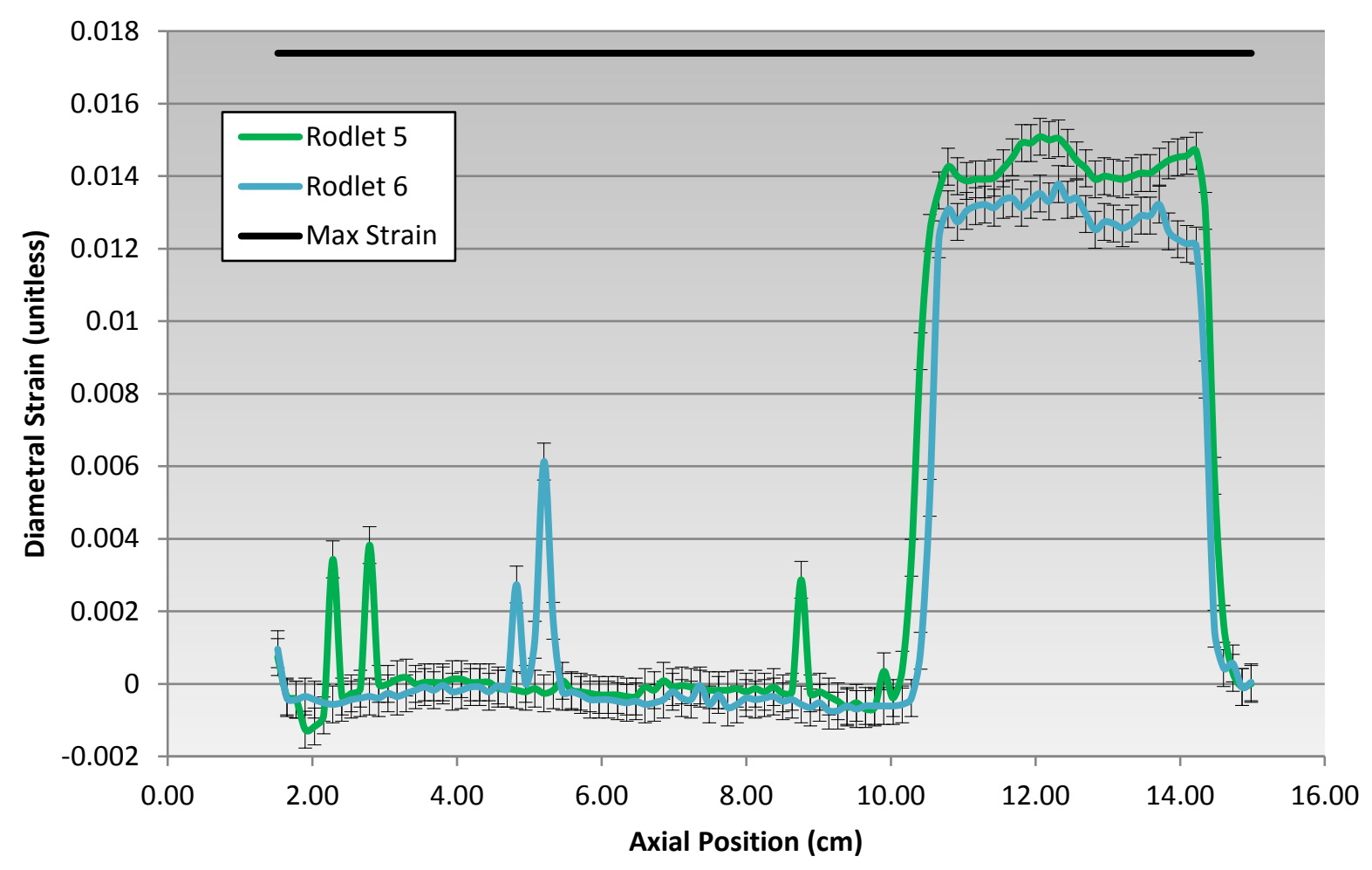

Figure 7. AFC-2D Rodlets 5 and 6 diametrical strain

\section{Destructive Examinations}

Destructive examination was carried out on AFC-2D R2, R3, R5, and R6. AFC-2D R1 was saved for future advanced non-destructive examination techniques. AFC-2D R4 was just a spacer in the AFC-2D capsule. Destructive examination is considered to start when the fuel pins are punctured for fission gas release analysis. Baseline destructive exams include fission gas release analysis, optical microscopy, microhardness testing and analytical chemistry analysis for burnup.

\subsection{Fission Gas Release}

Fission gases were collected from the rodlets using the HFEF Gas Assay, Sample, and Recharge (GASR) system. Rodlets were punctured using a $150 \mathrm{~W}$ Nd-YAG laser system and a gas sample was collected in a stainless steel bottle external to the hot cell. Void volume in the rodlet was then determined by a series of backfills into the punctured rodlet and expansions into the GASR system. The fuel rodlet internal gas pressure was derived from the void volume measurement and the initial gas pressure measurement upon puncture. Fission gas analysis was performed by gas mass spectrometry at Pacific Northwest National Laboratory (PNNL). Fission gas samples were also collected for future analysis at the INL Analytical Laboratory (AL) with a new gas mass spectrometry system. Results of fission gas analysis provided total elemental composition and krypton and xenon isotopic composition. A summary of results is shown in Table 2. The combined $\mathrm{Kr}$ and Xe release is based on an estimate of the number of fissions that occurred in each rodlet from $\mathrm{U}-235$ and $\mathrm{Pu}-239$ and an empirical relationship between fission and atoms of $\mathrm{Xe}$ and $\mathrm{Kr}$ produced. The number of fissions in each rodlet was determined from ICP-MS discussed in Section 5.4 along with some geometric scaling factors to scale from the chemistry sample size to the entire rodlet. The ratio of fission from U-235 to $\mathrm{Pu}-239$ was estimated from the $\mathrm{Kr}$ to $\mathrm{Xe}$ ratio present in the gas samples. For the Pu bearing AFC-2 samples $33 \%$ of fission was estimated to come from Pu-239, and for the AFC-3 samples all fission was assumed to come from U235 which is reasonable for these low burnup rodlets. The production of $\mathrm{Kr}$ and $\mathrm{Xe}$ is based on the fast fission yields of the stable $\mathrm{Kr}$ and $\mathrm{Xe}$ isotopes.

Only 3 AFC-2D pins (R2, R5, R6) were successfully evaluated on the GASR system for AFC-2D. AFC-2D R1 was not evaluated to save it as an archive sample. AFC-2D R4 was only a spacer element. AFC-2D R3 was evaluated 
on GASR, but the pin was breached and had filled with hot cell atmosphere. Fission gas release is high for oxide fuels at around 60\% release. There is also a significant amount of He in AFC-2D R5 and AFC-2D R6 from Am $\alpha$ decay.

The small volumes present in the AFC rodlets pose challenges for accurate pressure and volume measurements and calculations; small instrument uncertainties have a large effect on the calculated values (plenum pressure and volume). The pressure gauges in GASR are most accurate at full scale near $25 \mathrm{psi}$; however' initial puncture pressures for AFC rodlets were between 1 to 3 psi. Uncertainty in the as-built pressures and temperatures during fabrication also adds to uncertainty when calculating release fractions. Quantification of the uncertainties in the GASR system is an on-going process that is being actively researched. Currently repetition of the free volume determination measurement is used to produce a sample of measurements with a standard deviation between 1 and $2 \%$. However there may still be biases in the free volume determination that cannot be measured by repetition. Additionally, the initial puncture pressure for the AFC rodlets is not better than $1 \%$ accurate based on the stated uncertainty of the gauge by the manufacturer. Uncertainty in these initial puncture pressure and free volume determination combines to at least a 5\% uncertainty on the calculated plenum pressure. Recent efforts have been made to better characterize GASR response for larger fuel pins and higher plenum pressures by testing a set of well characterized standards. The results of this effort show GASR can produce reliable, repeatable results. In the future, a similar set of tests will be performed to better characterize the response of GASR to standards that represent the pressures and volumes seen in AFC rodlets.

Table 2. Fission Gas Release Summary

\begin{tabular}{|c|c|c|c|c|c|c|c|c|c|}
\hline \multirow{2}{*}{ Rodlet } & \multirow{2}{*}{$\begin{array}{c}\text { Plenum } \\
\text { Pressure } \\
\text { (psi) }\end{array}$} & \multirow{2}{*}{$\begin{array}{c}\text { Plenum } \\
\text { Volume } \\
\left(\mathrm{cm}^{3}\right)\end{array}$} & \multicolumn{6}{|c|}{ Gas Composition - Major Components (\%) } & \multirow{2}{*}{$\begin{array}{c}\mathrm{Kr}+\mathrm{Xe} \\
\text { Gas } \\
\text { Release } \\
(\%)\end{array}$} \\
\hline & & & $\mathrm{He}$ & $\mathbf{N}$ & 0 & $\mathrm{Ar}$ & $\mathrm{Kr}$ & Xe & \\
\hline \multicolumn{10}{|l|}{ AFC-2D R1 } \\
\hline AFC-2D R2 & 176.1 & 1.462 & 11.131 & $<0.001$ & 0.006 & 0.355 & 9.892 & 76.668 & $62.09 \%$ \\
\hline AFC-2D R3 & & & 0.044 & 6.112 & 0.066 & 93.790 & 0.00 & 0.00 & \\
\hline \multicolumn{10}{|l|}{ AFC-2D R4 } \\
\hline AFC-2D R5 & 269.1 & 1.495 & 31.818 & 0.077 & 0.001 & 0.235 & 7.428 & 58.728 & $63.37 \%$ \\
\hline AFC-2D R6 & 181.5 & 1.528 & 36.119 & 2.652 & 0.578 & 0.311 & 6.894 & 52.773 & $56.79 \%$ \\
\hline
\end{tabular}

\subsection{Optical Microscopy}

Optical microscopy was performed on fuel cross sections to investigate irradiation induced features in the fuel microstructure. Neutron radiography and the visual exams were used to guide the sectioning of the fuel in the approximate center of the fuel column. Approximately $6.25 \mathrm{~mm}$ of material was taken from the cross section area and placed in a met mount. Sectioning was achieved using a low speed saw with a diamond coated wafering blade. Custom stainless steel met mounts with an outer diameter of $2.5146 \pm 0.0076 \mathrm{~cm}(0.990 \pm 0.003 \mathrm{in}$.) were used for compatibility with the IMCL EPMA. The inner diameter of the met mounts was $1.27 \mathrm{~cm}$ in diameter and a groove that was later filled with epoxy was cut between the inner diameter and outer diameter to reduce the amount of steel present during grinding. The sectioned fuel was placed in the met mount and back filled with epoxy that contained approximately $15 \mathrm{wt} . \%$ graphite for conductivity. Again this was done to facilitate electron microscopy in future examinations. Fuel cross sections were ground and back potted periodically through the grinding process until a final polish was achieved. Grinding was achieved using 400 grit grinding plates followed by 800 and 1200 grit plates. Polishing was achieved using $6,3,1$, and $0.25 \mu \mathrm{m}$ diamond suspension. This produces a surface that is more than satisfactory for optical microscopy. Grinding and polishing were performed in the HFEF Containment Box (Window 2M). After polishing samples were transferred to the HFEF Met Box (Ar atmosphere) for examination on a Leitz MM5RT metallograph. Images were recorded with an integrated digital camera. Montages of the fuel cross sections were assembled from 50X images. Montages of scans across fuel cross sections were captured at both 100X and 200X. The light source was polarized during image collection, and images were captured in 8-bit color. Higher magnification images were recorded of features of interest.

A few important historic fuel performance criteria are worth noting when interpreting the observed microstructure. Fuel clad chemical interaction in oxide fuel with steel cladding has been well studied and is driven by the oxygen potential and volatile fission product content at the fuel clad gap [34, 35, 36]. 


\subsubsection{AFC-2D Optical Microscopy}

Four fuel cross sections were examined from AFC-2D (rodlets 2, 3, 5 and 6). These rodlets cover the MOX and MA-MOX with different O/M ratios irradiated in AFC-2D. The 50X montage images for AFC-2D are shown in Figure 8. Images were stitched together and blended using Adobe Photoshop CC using standard options. Central voids and central region grain restructuring occurred in R3 and R5 and appears to have almost started in R2. Fast reactor oxide fuels typically operate with fuel centerline temperatures greater than $1700^{\circ} \mathrm{C}$, leading to fuel restructuring with a central void and radial zone formation. Overall this central region formation is not as distinct as was seen in AFC-2C [5]. Unlike AFC-2C, the FCCI in AFC-2D is quite distinct especially in AFC-2D R3. Small white precipitates observed throughout the cross sections are likely the well-known 5 metal precipitates that consist of noble transition metals: $\mathrm{Mo}, \mathrm{Ru}, \mathrm{Tc}, \mathrm{Rh}$, and Pd [33]. Future electron microscopy examination of these cross sections should confirm this deduction.

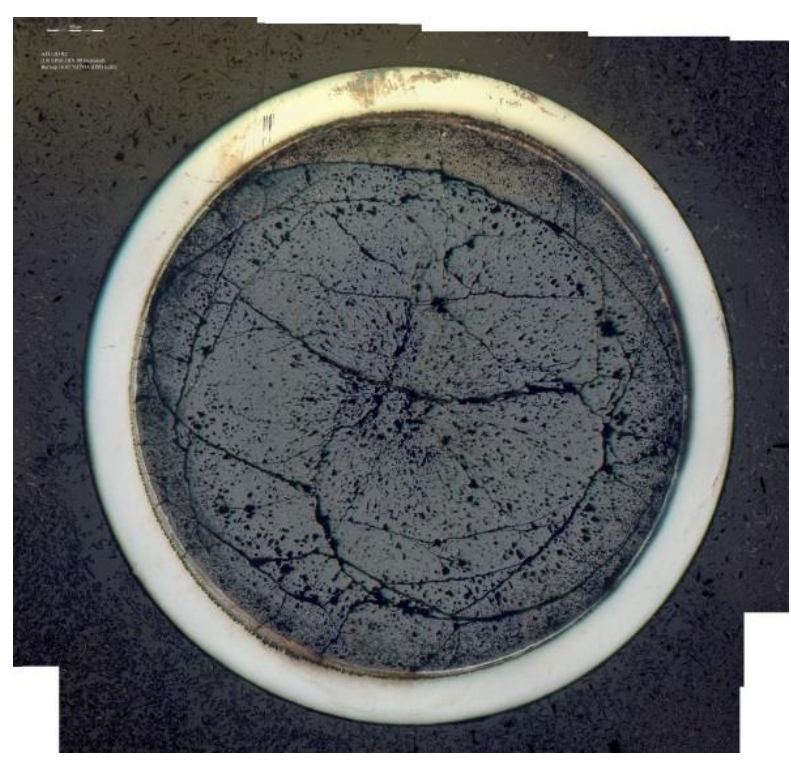

a) 2DR2 (MNT 09X)

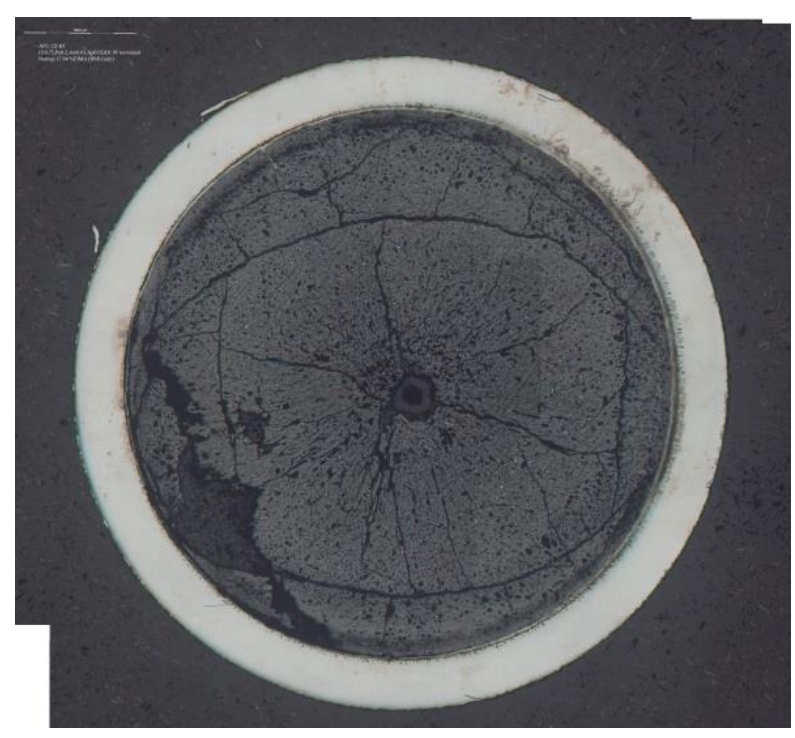

c) 2DR5 (MNT 11X)

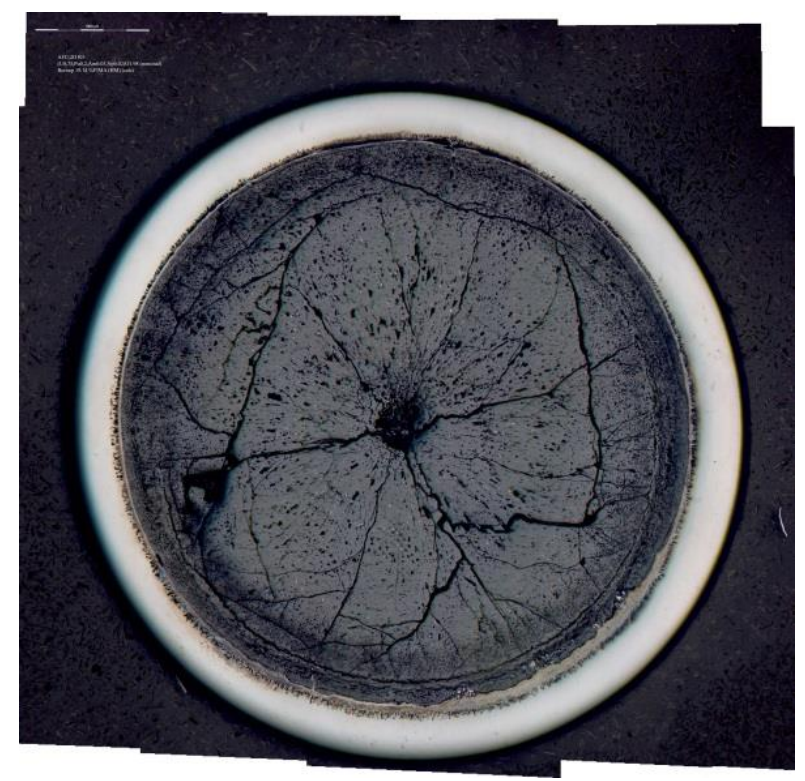

b) 2DR3 (MNT 10X)

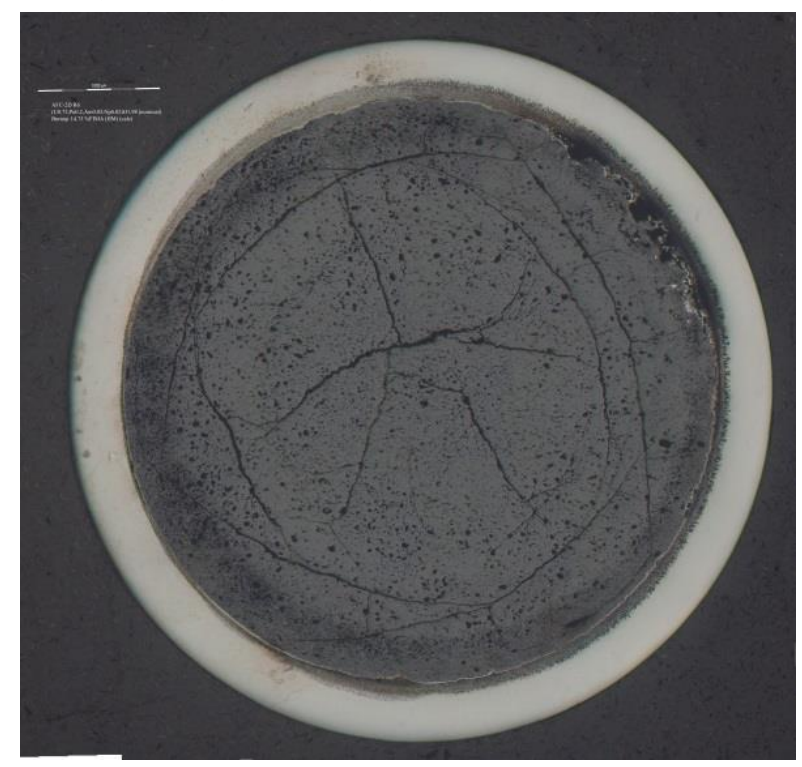

d) 2DR6 (MNT 12X)

Figure 8. AFC-2D optical microscopy (images recorded at 50X magnification) 
Fuel clad chemical interaction in oxide fuel with steel cladding has been well studied and is driven by the oxygen potential and volatile fission product content at the fuel clad gap [34, 35, 36]. Thus lower O/M ratio fuels should exhibit lower FCCI. This is observed in AFC-2D when comparing AFC-2D R3 (as-built $\mathrm{O} / \mathrm{M}=1.986$ ) and AFC-2D R5 (as-built $\mathrm{O} / \mathrm{M}=1.962$ ). This is illustrated in Figure 9 for the two cross sections. The FCCI zone in AFC-2D R3 varies from about $50 \mu \mathrm{m}$ to $200 \mu \mathrm{m}$, and a significant amount of cladding wastage has occurred in some areas up to $80 \mu \mathrm{m}$ of the original $444 \mu \mathrm{m}$ has been impacted by the FCCI. The FCCI layer is much smaller in AFC-2D R5. It is fairly consistent at $50 \pm 10 \mu \mathrm{m}$, and little wastage of the cladding has occurred.

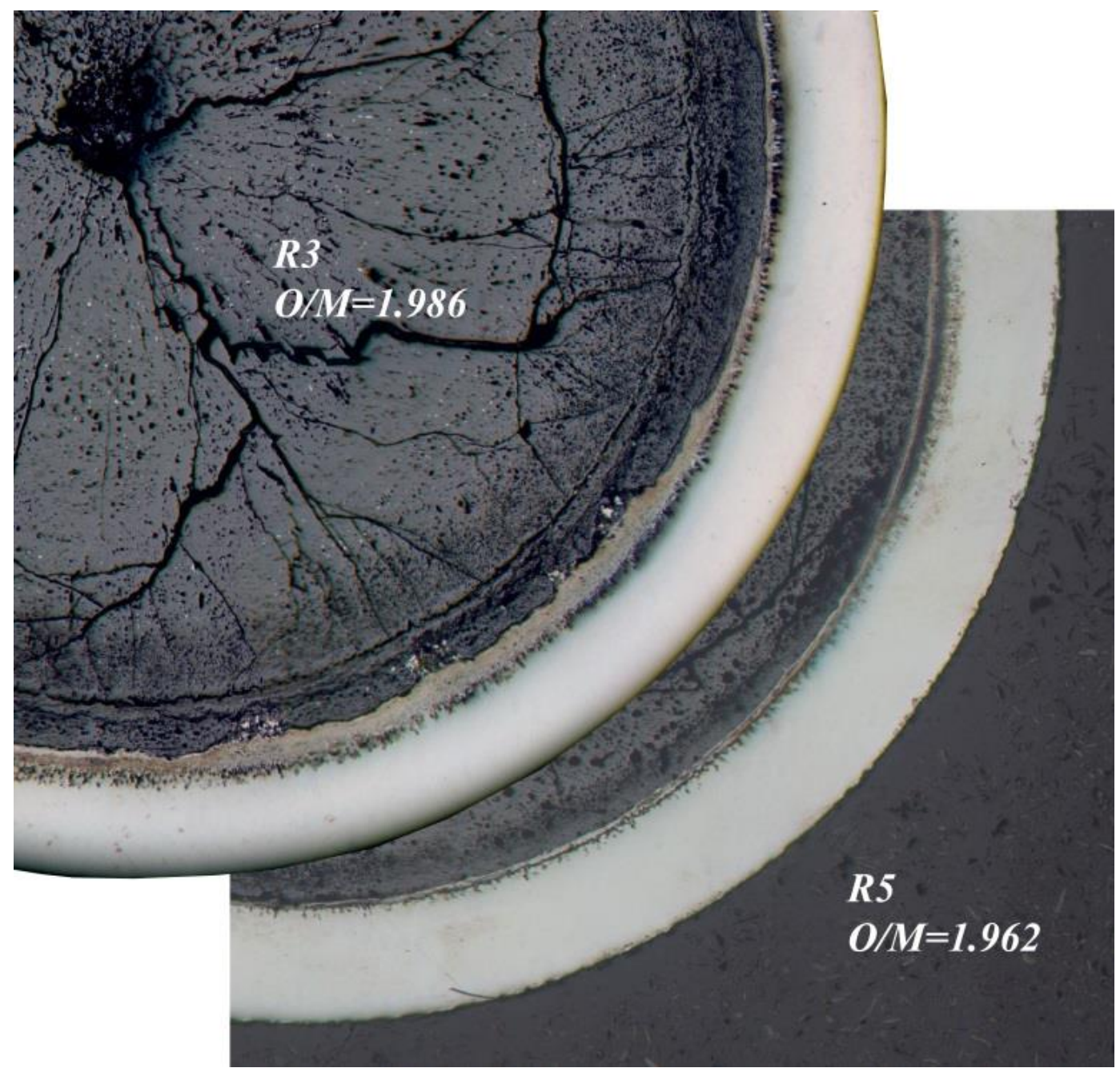

Figure 9. FCCI comparison between higher and lower O/M ratio MA-MOX of similar burnup

The additional highlight from the AFC-2D metallography was observed in the cross section from AFC-2D R6. No restructuring occurred in the observed cross section which left a fission gas bubble structure in place undisturbed by the rapid movement of porosity that occurs during restructuring. There are actually two unique fission gas bubble structures in the AFC-2D R6 cross section. In the more central region the fuel was operating at a temperature that was hot enough to sweep the fission gas out of each grain to the grain boundaries. This is illustrated in Figure 10. Further from the center of the cross section where the fuel was operating at lower temperatures, fission gas bubbles appear to be mostly intragranular and are only beginning to move towards the grain boundaries (see Figure 11). Microstructure observations of this nature are very useful for both fuel performance codes like BISON and microstructural evolution codes like MARMOT, and they have generated interest from the modeling community. Further work is planned with AFC-2D R6 to collect more information relevant to BISON, MARMOT and other NEAMS software. 


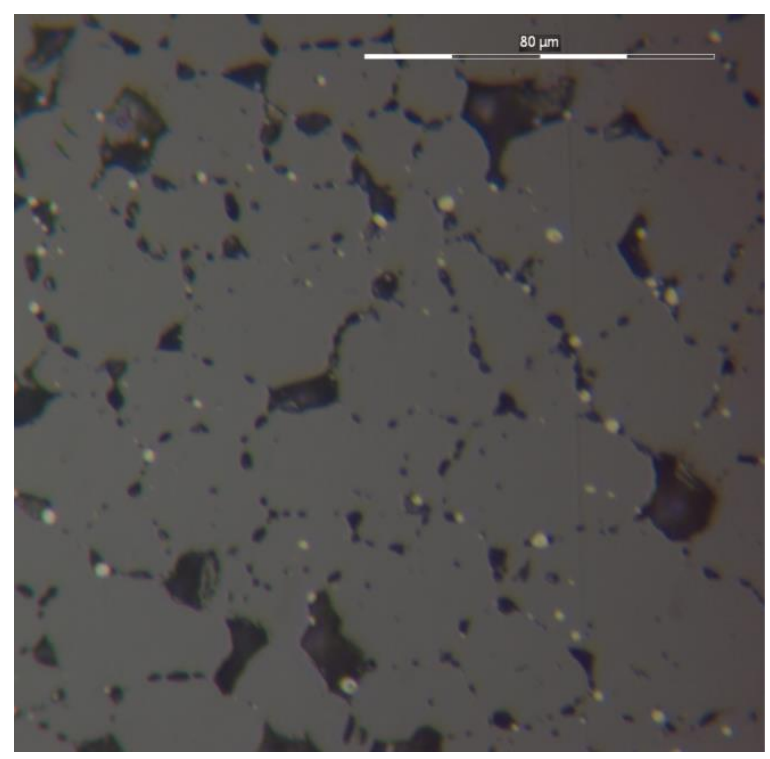

Figure 10. Fission gas bubbles on grain boundary in AFC-2D R6 cross section near center of the fuel (500X image)

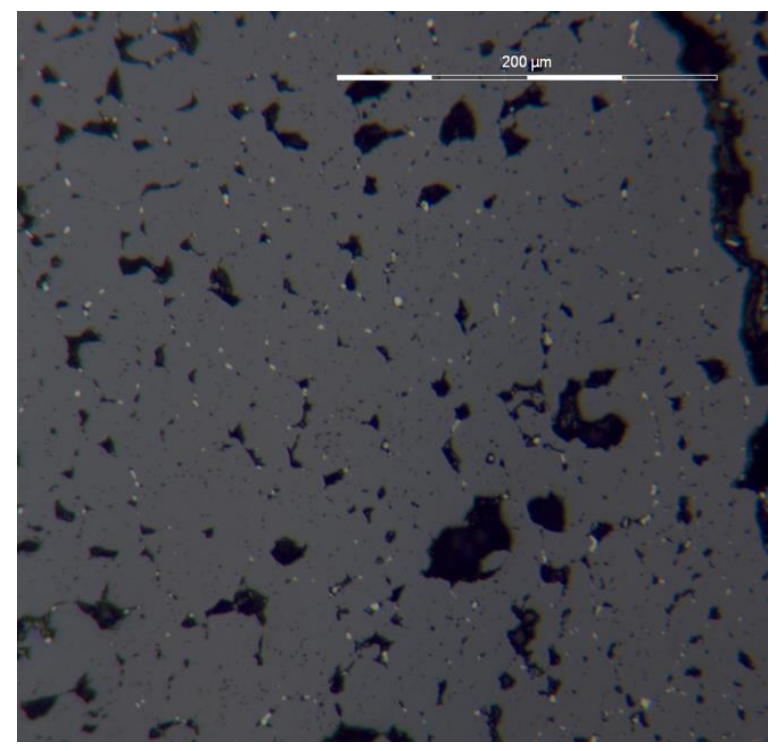

Figure 11. Intragranular fission gas bubbles in AFC-2D R6 cross section in the periphery of the fuel (200X image)

\subsection{Microhardness}

Microhardness testing was performed on the fuel met mounts using a LECO AMH43 microindentation hardness testing system installed in a shielded inert atmosphere alpha containment hot cell. Room temperature microhardness tests using a Vickers diamond pyramid were performed with a nominal load of $500 \mathrm{~g}$. The primary intent of microhardness testing is to identify changes in cladding mechanical properties that may be due to interaction between fuel and cladding. Decreases in cladding hardness (softening) may indicate cladding decarburization. Increases in cladding hardness (hardening) indicate FCCI between rare earth elements and the cladding.

A summary of the microhardness for cladding, FCCI layers, and fuel is given in Table 3. A reference hardness for unirradiated HT-9 cladding is $\mathrm{H}_{\mathrm{v}}=295$ [37]. Hardness values for cladding below this value may be indicative of the elevated temperatures that the cladding experienced in these irradiation tests. Radiation should harden the cladding at high enough dpa, but no dpa data is available for the cladding in these experiments to compare against literature. When present in metallic fuel, the FCCI zone is harder than the other fuel components. The oxide FCCI layer is highly variable due partially to extensive porosity in this layer. The hardness in the fuel in both the oxides and the metallic 
samples is also highly variable. No clear radial trends were observed in the samples, although this is not surprising considering the variety of samples examined in these experiments.

Table 3. Summary of microhardness testing from different rodlet cross sections

\begin{tabular}{llll}
\hline Rodlet & Cladding & FCCI & Fuel \\
\hline AFC-2D R2 & $217.3 \pm 16.6$ & $129.3 \pm 33.4$ & $533.5 \pm 209.7$ \\
AFC-2D R3 & $220.6 \pm 23.1$ & $398.7 \pm 224.5$ & $675.8 \pm 216.0$ \\
AFC-2D R5 & $251.6 \pm 39.8$ & $353.4 \pm 174.0$ & $694.6 \pm 201.2$ \\
AFC-2D R6 & $259.0 \pm 39.7$ & $141.7 \pm 79.1$ & $609.8 \pm 166.0$ \\
\hline
\end{tabular}

\subsection{Analytical Chemistry}

During rodlet sectioning to create the microscopy samples, additional samples were taken from near the fuel stack center and sent to the INL Analytical Laboratory (AL) for a variety of chemical and radiological analyses. The primary goal of the analysis is to ascertain the burnup of the sampled material. Gamma spectrometry analysis is also performed. Axial variations in burnup along a rodlet, if any exist, can typically be scaled by comparing quantitative gamma spectrometry results from the AL to semi-quantitative results from PGS. Mass spectrometry analysis can also provide information on the destruction of actinides and minor actinides. Minor actinide destruction is an essential feature of transmutation fuel, but the quasi-fast neutron spectrum that is really an epithermal neutron spectrum created by the $\mathrm{Cd}$ baskets used in this experiment does not produce a minor actinide mix in the fuel that is representative of the minor actinide mix seen in actual fast reactor fuel like EBR-II.

Burnup is calculated from the results of mass spectrometry examinations of dissolved fuel samples. Samples are placed in a heated acid solution until both the fuel alloy or compound and the cladding have dissolved. Care is taken to ensure complete dissolution of all constituents which can take up to 24 hours to complete. Precipitates were a particular problem in the MOX and MA-MOX samples where it is often difficult to get the 5 transition metal precipitates seen in optical microscopy into solution. The MOX and MA-MOX samples were dissolved in 8M nitric acid kept near boiling for 24 hours.

Original solutions are saved for archive or if a reanalysis is necessary. Aliquots of the original dissolution are diluted and sent through different inductively coupled plasma mass spectrometry devices (ICP-MS). Samples are sent through an ICP-AES (atomic emission spectrometry) to determine the cladding and sodium weight of the sample. Samples are then sent through an ICP-MS to determine the isotopic composition of the major constituents and fission products. In many cases there are isobaric (same atomic number) interferences that prevent exact identification of isotopic species. In the fission product data, isobaric interferences were not considered significant to the conclusions of this study, so no additional separations were performed to clear these interferences. Multi-collector ICP-MS (MCICP-MS) was performed on aliquots to determine the isotopic composition of the actinides. Isobaric interferences were considered significant in the actinides. A chemical separation to remove the Pu from the solution was performed to get $\mathrm{Pu}$ specific isotopics by mass spectrometry. These results were then compared to alpha spectrometry analysis of the same solutions and resulted in good agreement. The MC-ICP-MS results for both the original solution and the $\mathrm{Pu}$ separation were able to produce isotope specific results for U-234, U-235, U-236, U-238, Pu-238, Pu-239, Pu-240, $\mathrm{Pu}-241, \mathrm{Pu}-242, \mathrm{~Np}-237, \mathrm{Am}-241$, and $\mathrm{Cm}-244$. No attempt was made to separate Am and Cm. The combined mass of Am-242 and Cm-242 is known as well as the combined mass of Am-243 and Cm-243. Higher mass minor actinides were not measured. The final results from AL are archived as AL reports (log number 98656 to 98663 for AFC-2D).

The determination of burnup was performed using the measured mass of a specific fission product in the fuel, the cumulative fission yield of that specific fission product, and the total mass of actinides present in the sample. This method is sometimes referred to as the "Fission Product Monitor - Residual Heavy Atom" technique [38, 39]. Ideally, the fission products used in the calculations should have a small neutron absorption cross section, a high cumulative fission yield, and a similar fission yield for that nuclear isobar between $\mathrm{U}$ and $\mathrm{Pu}$ fission. Chemically the fission product must also readily dissolve during the leaching process. This technique uses the following formula to calculate burnup $(B U)$ based on a specific fission product detected in the ICP-MS spectrum. Burnup is calculated in \% fission per initial heavy metal atoms (FIMA) which is comparable to heavy metal depletion and atom \% burnup units used in other sources. 


$$
B U=\frac{\left(N_{f p} / y_{f p}\right)}{\left(\left(N_{f p} / y_{f p}\right)+N_{A c t}\right)} \times 100
$$

Where $N_{f p}$ is number of atoms of a specific fission product $f p$ measured in the sample, $y_{f p}$ is the cumulative fission yield of fission product $f p$, and $N_{A c t}$ is the number of atoms of actinides in the sample. All fission yields were taken from ENDF/B-VII.1 [40]. In the AFC-2 tests, enough fission occurred in actinides other than U-235 that the burnup would be biased if only the U-235 cumulative fission yield was used in Equation (1). The $\mathrm{Kr}$ to $\mathrm{Xe}$ ratio found in the fission gas release exams was used to estimate the fraction of U-235 and Pu-239 fissions in the experiments, and no other fissile or fissionable isotopes (e.g., Am-241, Am-243m, U-238, etc.) were considered. For the AFC-2 samples $33 \%$ of the fission was assumed to come from $\mathrm{Pu}-239$, and for the AFC-3 samples all fission was considered to have come from U-235. Effective yields are created as a weighted average of the different fission product yields based on the relative amount of fission that occurred in different actinides over the course of the experiment. A benefit of this burnup technique is that it requires no a priori knowledge of the sample. All the factors in Equation 1 can be directly measured from mass spectrometry results and no assumptions about the pre-irradiation state of the fuel or the size of the sampled material need to be made. The described technique is largely similar to the more standardized Nd-148 burnup technique (ASTM E321). However ASTM E321 requires a difficult Nd separation to remove Sm-148 and a correction to account for neutron absorption in Nd-148 that is only valid for thermal spectrum systems. Historically the "Fission Product Monitor - Residual Heavy Atom" technique has performed quite well in the evaluation of EBRII fuel.

There are six isotopes that work reliably for the ICP-MS technique in the AFC-2D/E and AFC-3A/B fuel: La-139, Ce-140, Ce-142, Pr-141, Nd-145, and Nd-146. It should be noted that these same isotopes cannot be used in the case of simulated recycle (AFC-2A, AFC-2B) where fuel begins irradiation with mass percent levels of various rare earths. These isotopes occur on the higher atomic number peak of the bimodal fission product distribution. They are all lanthanides that will readily dissolve in the selected acid. The differences between U-235 yield and Pu-239 yield are fairly small for these isotopes as well. All these isotopes are nonradioactive and have relatively small neutron absorption cross section with the exception of Nd-145. Because of its cross section, the number of Nd-145 and Nd-146 atoms in the samples and their respective yields are summed in the calculation of burnup. In this calculation, the burnup measurement for each sample of particles was found by taking the average of the individual isotope results from Equation (1) for La-139, Ce-140, Ce-142, Pr-141, and the Nd-145 + Nd-146 combined result. The uncertainty of all mass spectrometry values is no better than 5\%, and the derived burnup values are also considered no better than $5 \%$ relative uncertainty. The derived burnup values and the burnup from simulation for each rodlet are shown in Table 4 for AFC-2D. For AFC-2, the simulations over predict the measured burnup by 29 to $37 \%$. The source of this bias is anticipated to be explored further in future reanalysis of the AFC-2 experiments.

Table 4. Burnup values for AFC-2D

\begin{tabular}{ccc}
\hline Rodlet & $\begin{array}{c}\text { Preliminary } \\
\text { Burnup } \\
\text { (\%FIMA) }\end{array}$ & Simulation[28] \\
\hline AFC-2D R1 & Archive & $13.32 \%$ \\
\hline AFC-2D R2 & $12.2 \%$ & $16.85 \%$ \\
\hline AFC-2D R3 & $14.2 \%$ & $19.14 \%$ \\
\hline AFC-2D R5 & $13.4 \%$ & $17.94 \%$ \\
\hline AFC-2D R6 & $10.6 \%$ & $14.75 \%$ \\
\hline
\end{tabular}




\section{Summary}

Baseline PIE has been completed on rodlets from AFC-2D. This includes visual exams, neutron radiography, gamma spectrometry, dimensional inspection, fission gas release evaluation, optical microscopy, microhardness evaluation, and chemical analysis. The results compiled in this report offer an overall evaluation of the performance of the tested fuel systems. Baseline PIE provides an engineering or macroscopic scale evaluation of fuel performance and prepares samples for a more detailed phenomenological study of observed performance. Advanced PIE techniques are desired to obtain microscopic elemental and structural information both in the fuel, in the cladding, and in the interface where the composition of the FCCI layer is of great interest.

The AFC-2D rodlets were run at temperatures in excess of typical operating conditions likely resulting in the cladding strain and FCCI observed in this system. However the microstructure present in AFC-2D R6 and other samples should provide an interesting case study for further evaluation by electron microscopy and for comparison to simulation using different NEAMS tools. 


\section{References}

1. Report to Congress on the Advanced Fuel Cycle Initiative: The Future Path for Advanced Spent Fuel Treatment and Transmutation Research, U.S. Department of Energy Office of Nuclear Science and Technology, January 2003

2. FCRD Advanced Fuels Campaign Execution Plan, FCRD-FUEL-2011-000105, INL/EXT-10-18954, Rev. 3, June 2013.

3. BA Hilton, DL Porter, SL Hayes, "AFC-1 Transmutation Fuels Post-Irradiation Hot Cell Examination 4 to 8 at.\% Final Report,” INL/EXT-05-00785, Rev. 1, 2006

4. SL Hayes, "Irradiation of Metallic Fuels with Rare Earth Additions for Actinide Transmutation in the Advanced Test Reactor Experiment Description for AFC-2A and AFC-2B," INL/EXT-06-11707 Rev. 1, 2006

5. H.J.M. Chichester, D.L. Porter, "Postirradiation Examination of AFC-2B and AFC-2C Experiments," INL/LTD12-26154, Idaho National Laboratory, 2012.

6. G.L. Hofman, L.C. Walters, T.H. Bauer, Metallic fast reactor fuels, Progress in Nuclear Energy, Volume 31, Issues 1-2, 1997, Pages 83-110, ISSN 0149-1970, http://dx.doi.org/10.1016/0149-1970(96)00005-4.

7. G.L. Hofman, S.L. Hayes, M.C. Petri, Temperature gradient driven constituent redistribution in U $-\mathrm{Zr}$ alloys, Journal of Nuclear Materials, Volume 227, Issue 3, January 1996, Pages 277-286, ISSN 0022-3115, http://dx.doi.org/10.1016/0022-3115(95)00129-8.

8. Douglas C. Crawford, Douglas L. Porter, Steven L. Hayes, Fuels for sodium-cooled fast reactors: US perspective, Journal of Nuclear Materials, Volume 371, Issues 1-3, 15 September 2007, Pages 202-231, ISSN 0022-3115, http://dx.doi.org/10.1016/j.jnucmat.2007.05.010.

9. W.J. Carmack, D.L. Porter, Y.I. Chang, S.L. Hayes, M.K. Meyer, D.E. Burkes, C.B. Lee, T. Mizuno, F. Delage, J. Somers, Metallic fuels for advanced reactors, Journal of Nuclear Materials, Volume 392, Issue 2, 15 July 2009, Pages 139-150, ISSN 0022-3115, http://dx.doi.org/10.1016/j.jnucmat.2009.03.007.

10. H.J.M. Chichester, "Postirradiation Examination Plan for AFC-2 Metallic and Oxide Fuels," PLN-3773, Idaho National Laboratory, 2011

11. J.M. Harp, "Post irradiation Examination Plan for AFC-OS Irradiation Experiments," PLN-4371, Idaho National Laboratory, 2014

12. R.E. Mason et al., "AFC2-C/D Fuel Pellet Data Package," LA-UR-08-03727, 2008

13. AFC-2C and AFC-2D Rodlet As-Built Data Package, INL internal document, INL RD-General Projects, https://edms/pls/edms/toto.dmx 3?f doc $=2943947$ (INL only)

14. H.J. MacLean, "Irradiation of AFC-2C and -2D Oxide Fuels for Actinide Transmutation in the ATR," PLN2764, Idaho National Laboratory, 2008

15. M.A. Lillo, G.S. Chang, "Cycle 143A Physics Evaluations Of AFC-2C And -2D Tests In The East Flux Trap," ECAR-385, Idaho National Laboratory, 2008

16. M.A. Lillo, G.S. Chang, "Cycle 143B Physics Evaluations Of AFC-2B, -2C And -2D Tests In The East Flux Trap," ECAR-482, Idaho National Laboratory, 2008

17. J.R. Mitchell, G.S. Chang, "Cycle 144A Physics Evaluations Of AFC-2B, -2C And -2D Tests In The East Flux Trap," ECAR-545, Idaho National Laboratory, 2009

18. J.R. Mitchell, G.S. Chang, "Cycle 145A Physics Evaluation of the AFC-2 Experiment in the East Flux Trap," ECAR-622, Idaho National Laboratory, 2009

19. J.R. Mitchell, G.S. Chang, "Cycle 145B Physics Evaluation Of The AFC-2 Experiment In The East Flux Trap," ECAR-825, Idaho National Laboratory, 2009

20. J.R. Mitchell, G.S. Chang, "Cycle 146A Physics Evaluation of the AFC-2 Experiment in the East Flux Trap", ECAR-893, Idaho National Laboratory, 2009

21. J.R. Mitchell, G.S. Chang, "Cycle 146B Physics Evaluation of the AFC-2 Experiment in the East Flux Trap", ECAR-983, Idaho National Laboratory, 2010

22. J.R. Mitchell, G.S. Chang, "Cycle 147A Physics Evaluation of the AFC-2 Experiment in the East Flux Trap", ECAR-1062, Idaho National Laboratory, 2010

23. J.R. Mitchell, G.S. Chang, "Cycle 148A Physics Evaluation of the AFC-2 Experiment in the East Flux Trap", ECAR-1177, Idaho National Laboratory, 2010

24. J.R. Mitchell, G.S. Chang, "Cycle 148B Physics Evaluation of the AFC-2 Experiment in the East Flux Trap", ECAR-1261, Idaho National Laboratory, 2010

25. J.R. Mitchell, G.S. Chang, "Cycle 149A Physics Evaluation Of The AFC-2 Experiment In The East Flux Trap", ECAR-1418, Idaho National Laboratory, 2011 
26. J.R. Mitchell, G.S. Chang, "Cycle 149B Physics Evaluation Of The AFC-2 Experiment In The East Flux Trap", ECAR-1551, Idaho National Laboratory, 2011

27. J.R. Mitchell, G.S. Chang, "Cycle 150B Physics Evaluation Of The AFC-2 Experiment In The East Flux Trap", ECAR-1658, Idaho National Laboratory, 2011

28. J.R. Mitchell, G.S. Chang, "Cycle 150B As-Run Physics Evaluation Of The AFC-2 Experiment In The East Flux Trap,” ECAR-1762 Idaho National Laboratory, 2012

29. C. R. Glass and G. S. Chang, "Physics Analysis for the AFC-3 Series Tests Specimens Designated for Insertion during Cycle 150-B into ATR Positions A-10 and A-11," ECAR-1514, Rev. 1, 2011

30. M.A. Lillo, C.R. Glass, G.S. Chang, "ATR Cycle 150B Projected Physics Evaluations for the AFC-3A and -3B Experiments in the A-1 0 and A-11 Positions" ECAR-1677, Idaho National Laboratory, 2011

31. C.R. Glass, G.S. Chang, "ATR Cycle 151A As-run and 151B Projected Physics Evaluations for the AFC-3A and -3B Experiments in the A-10 and A-11 Positions," ECAR-1816

32. C.R. Glass, G.S. Chang, "ATR Cycle 151B As-run Physics Evaluations for the AFC-3A and -3B Experiments in the A-10 and A-11 Positions," ECAR-2128, Idaho National Laboratory, 2012

33. D. R. Olander, "Fundamental Aspects of Nuclear Reactor Fuel Elements," Energy Research and Development Administration (ERDA) Technical Document TID-26711-P1, 1976.

34. Lawrence, L.A., F.E. Bard, and N.S. Cannon. "Cladding Inner Surface Wastage for Mixed-Oxide Liquid Metal Reactor Fuel Pins.” United States: OSTI Identifier 6345371, 1990.

35. M.G. Adamson, E.A. Aitken, "On the Cs,Te fission product-induced attack and embrittlement of stainless steel cladding in oxide fuel pins," Journal of Nuclear Materials, Volume 132, Issue 2, June 1985, Pages 160-166, ISSN 0022-3115, http://dx.doi.org/10.1016/0022-3115(85)90410-6.

36. J.D.B. Lambert, R. Strain, Oxide Fuels, R.W. Cahn, P. Hassen, E.J. Kramer (Eds.), Material Science and Technology, 10AVCH, Germany (1994) Chapter 3

37. Thak Sang Byun, Jong-Hyuk Baek, Osman Anderoglu, Stuart A. Maloy, Mychailo B. Toloczko, Thermal annealing recovery of fracture toughness in HT9 steel after irradiation to high doses, Journal of Nuclear Materials, Volume 449, Issues 1-3, June 2014, Pages 263-272, ISSN 0022-3115, http://dx.doi.org/10.1016/j.jnucmat.2013.07.064.

38. Maeck, W.J., Larsen, R.P., Rein, J.E., "Burnup Determination for Fast Reactor Fuels: A Review and Status of the Nuclear Data and Analytical Chemistry Methodology Requirements," NTIS Report TID 26209, 1973

39. J.M. Harp, P.A. Demkowicz, P.L. Winston, J.W. Sterbentz, "An analysis of nuclear fuel burnup in the AGR-1 TRISO fuel experiment using gamma spectrometry, mass spectrometry, and computational simulation techniques," Nuclear Engineering and Design, 278, 395-405, (2014) http://dx.doi.org/10.1016/j.nucengdes.2014.07.041

40. Chadwick, M. B., et al. "ENDF/B-VII. 1 nuclear data for science and technology: cross sections, covariances, fission product yields and decay data." Nuclear Data Sheets 112.12: 2887-2996. 2011 


\section{Appendix A \\ Rodlet Visual Exams}

AFC-2D

AFC-2D R1

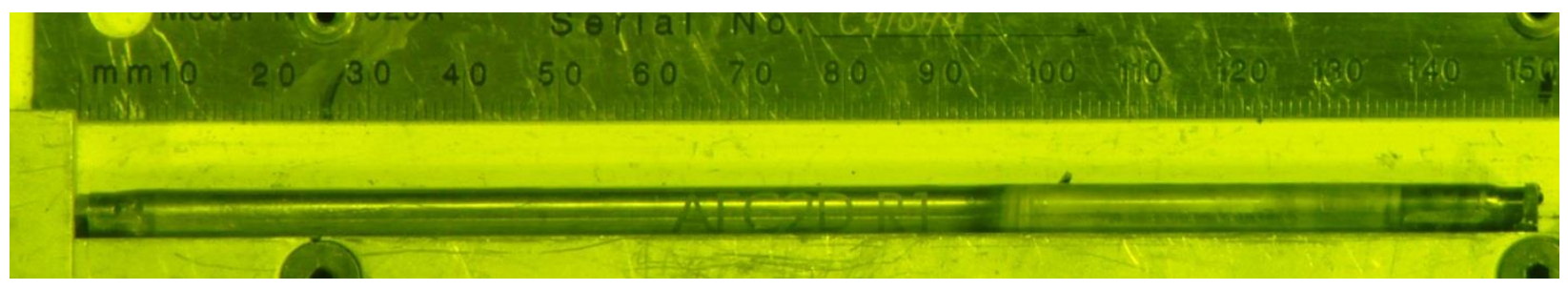

AFC-2D R2

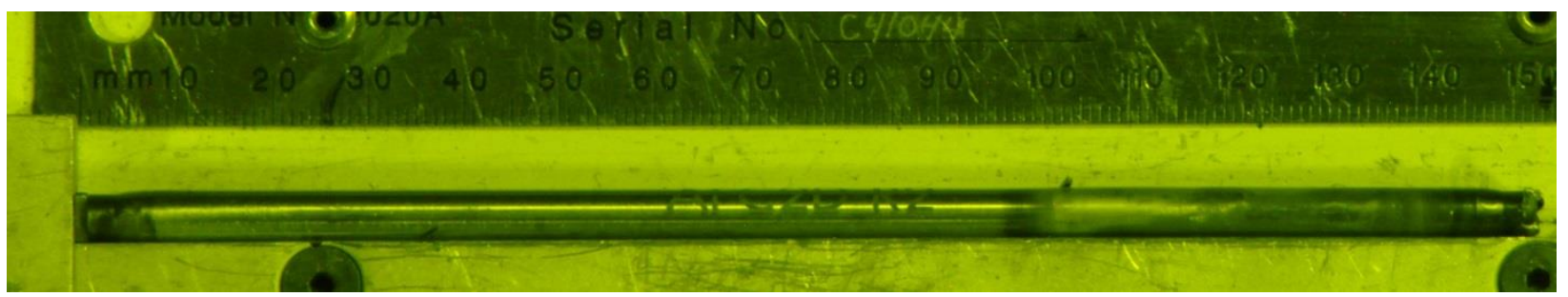

AFC-2D R3

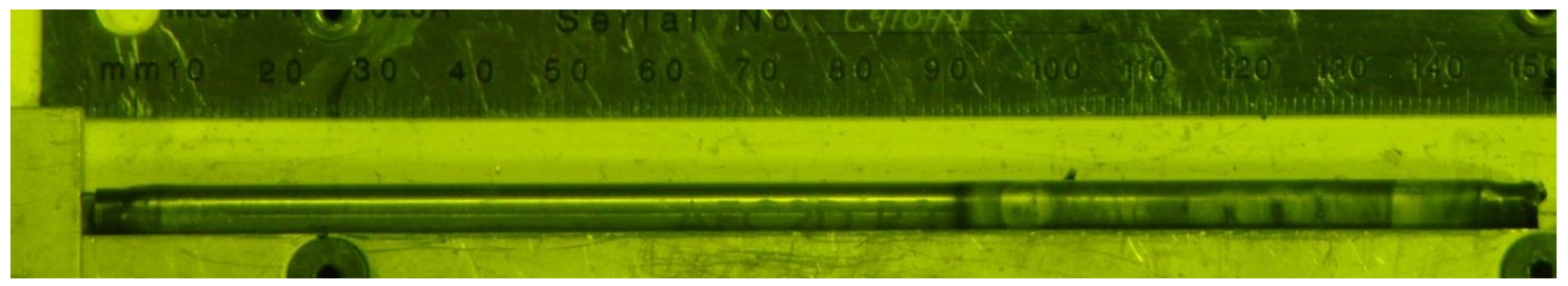

AFC-2D R4 (empty rodlet)

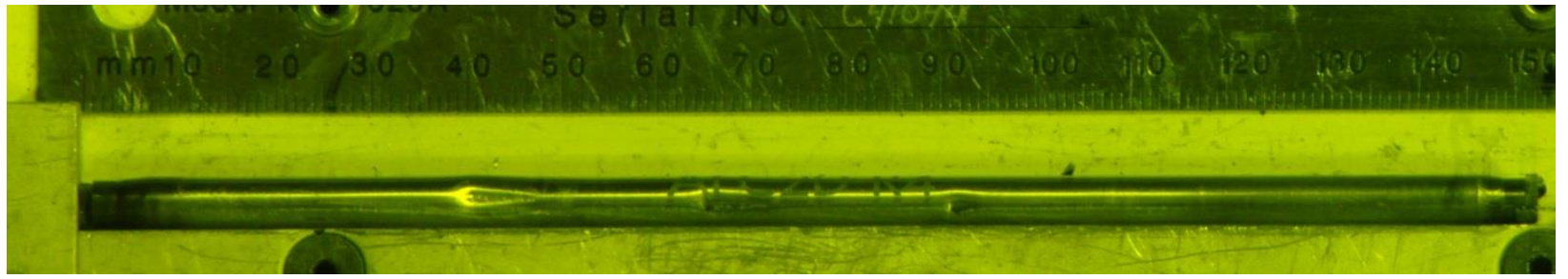


AFC-2D R5

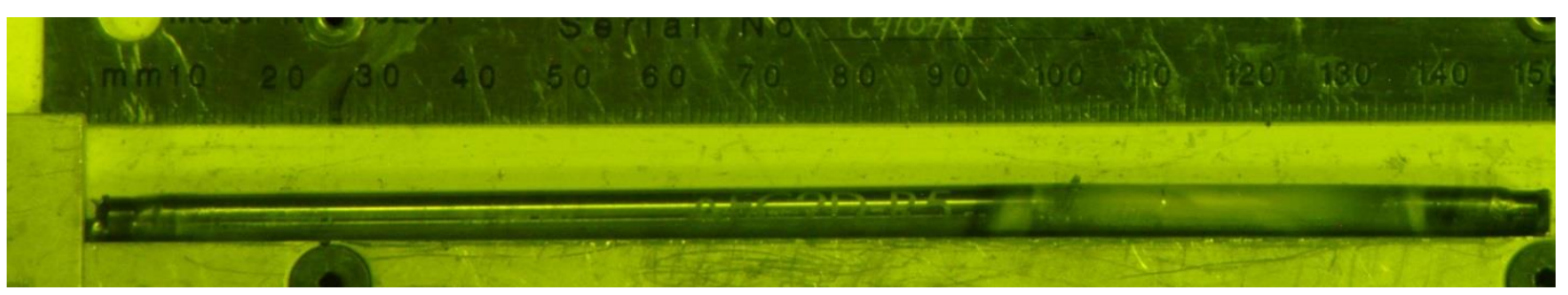

AFC-2D R6

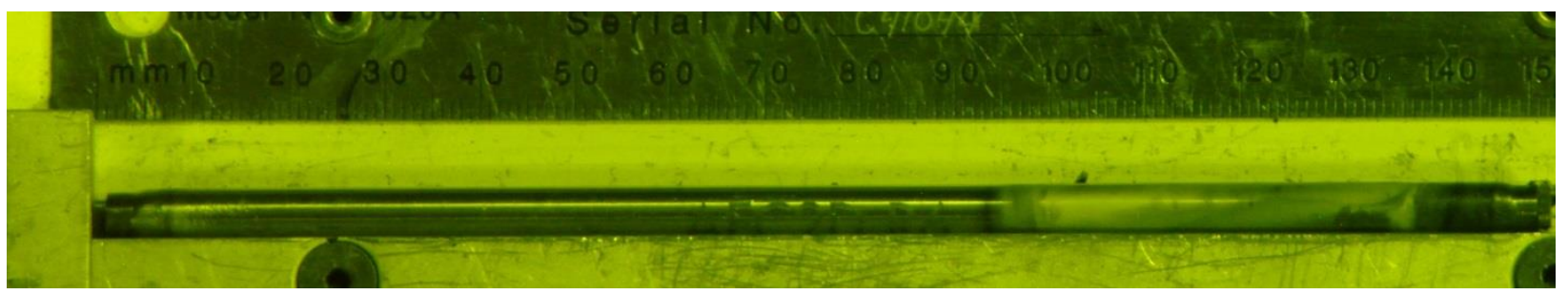




\section{Appendix B \\ Gamma Spectrometry of Rodlets}

AFC-2D

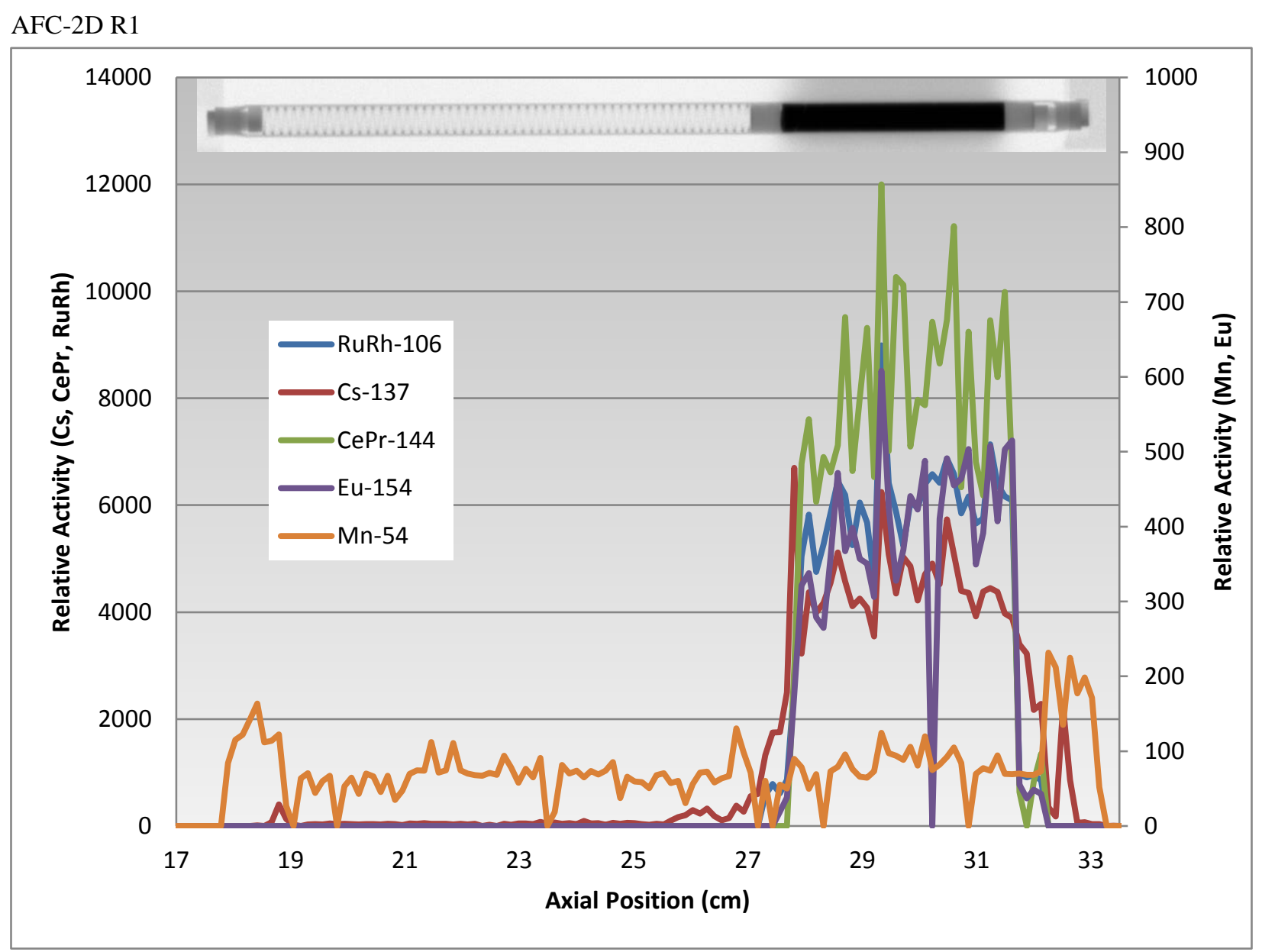


AFC-2D R2

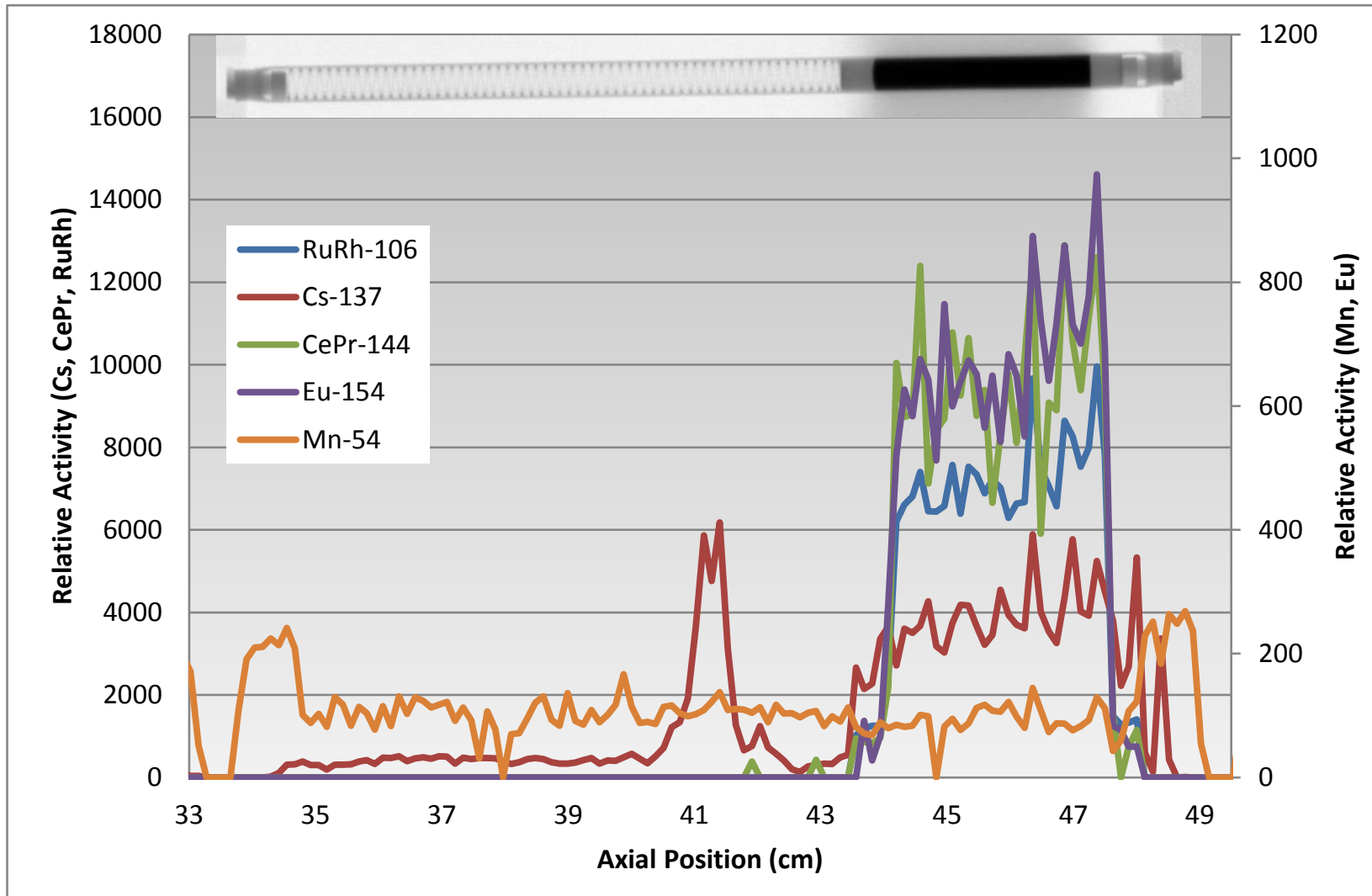

AFC-2D R3

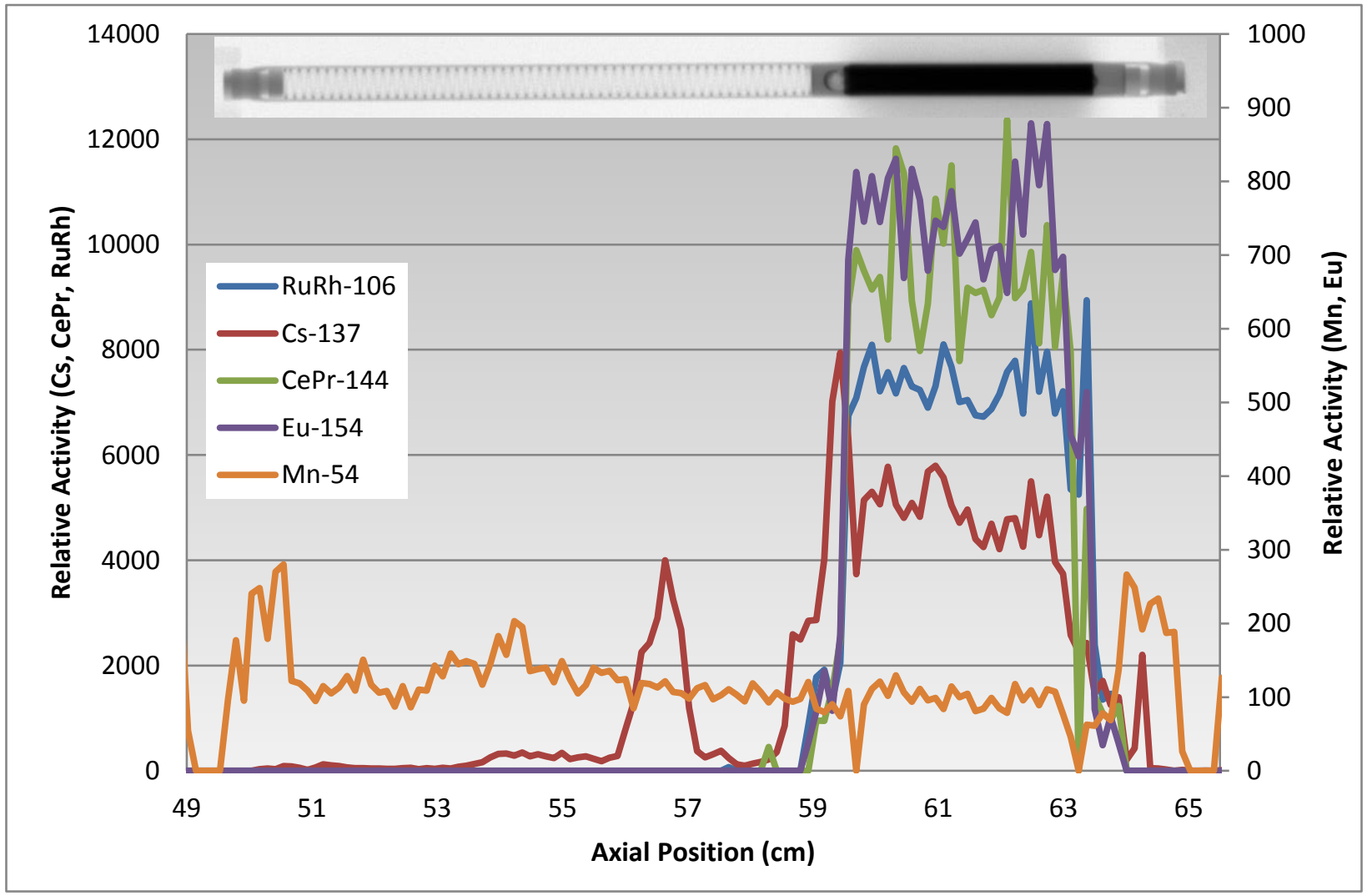


AFC-2D R5

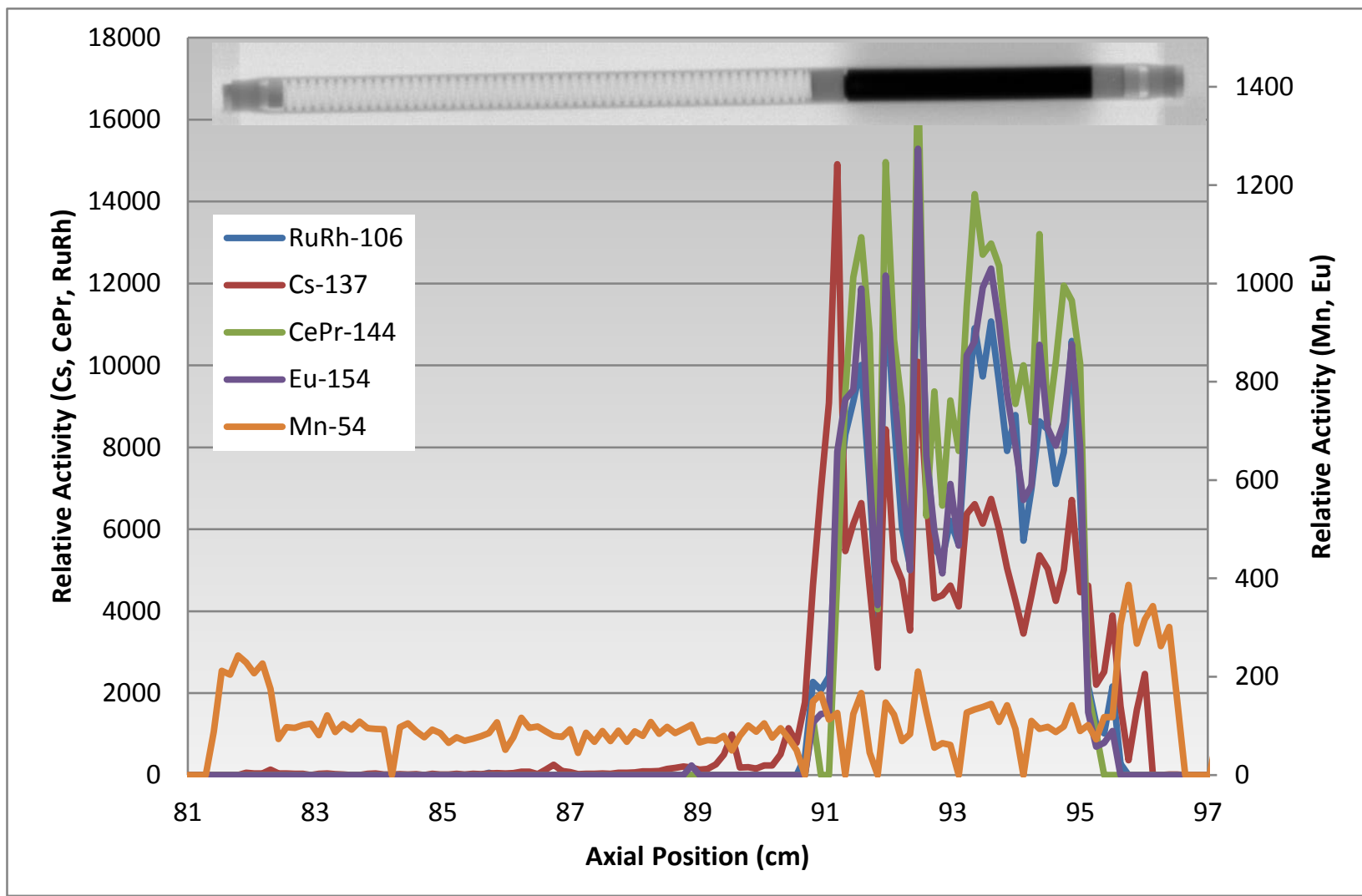

AFC-2D R6

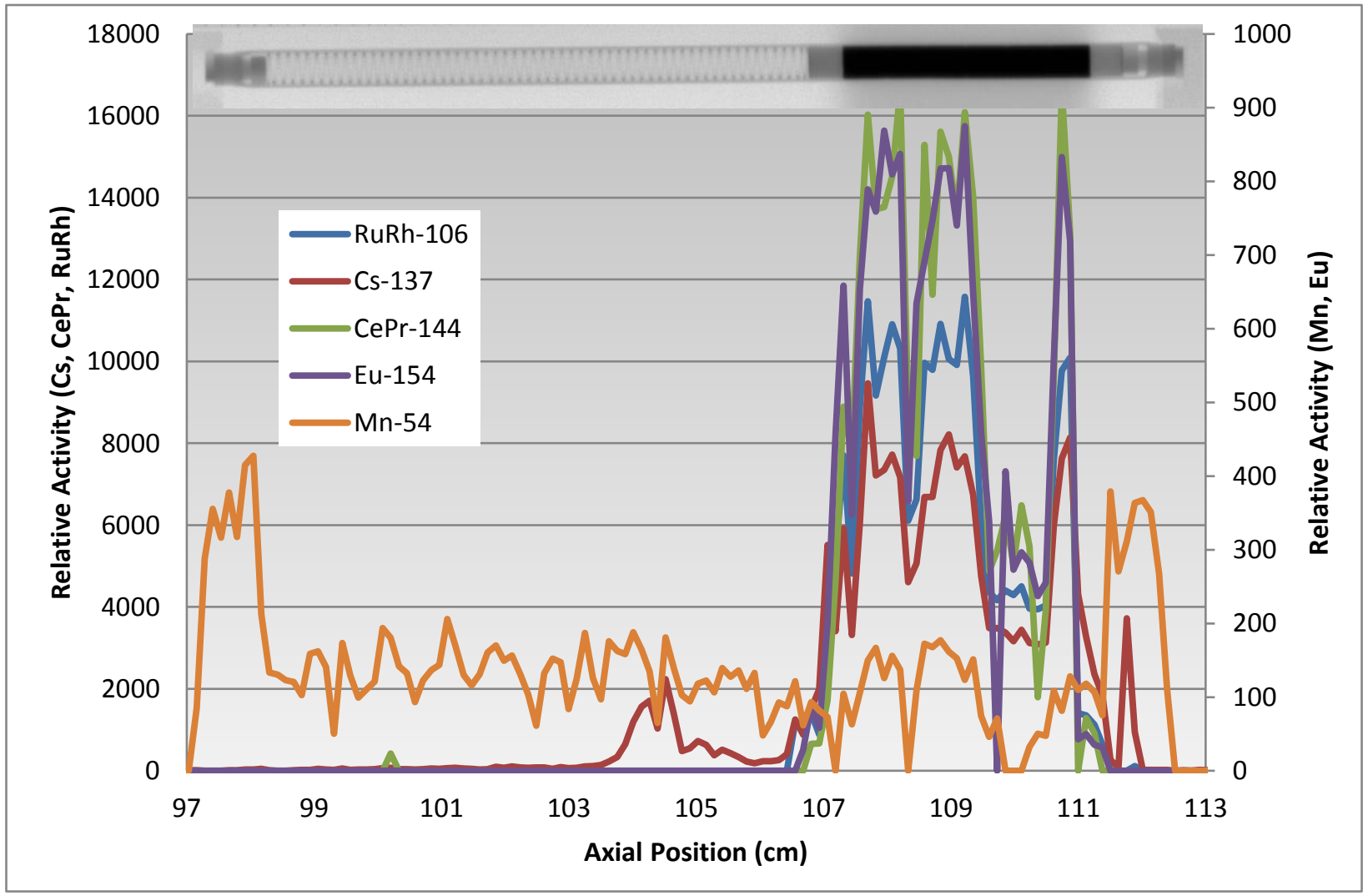


